\title{
XXI.
}

\section{Ueber Malariakrankheiten und einige andere Infectionskrankheiten in Vera Cruz, und Bemerkung zur Aetiologie des Spasmus glottidis.}

Von Dr. Carl Heinemann in Vera Cruz.

\section{Ueber Malariakrankheiten in Vera Cruz, mit Berücksichtigung der gesammten Ostküste und der Hauptstadt Mexico's.}

Unter den an der Golfküste Mexico's endemisch herrschenden Krankheiten nehmen die Malariakrankheiten, was Hänfigkeit und allgemeine Verbreitung betrifft, unstreitig den ersten Rang ein, sie bilden aber auch durch die Mannichfaltigkeit ihrer Erscheinungsform und ihre Bösartigkeit einen dominirenden Factor im Krankheitsbilde jener Gegenden.

Obgleich mir die Literatur über Malaria in den Tropen nur in sehr beschränktem Maasse zu Gebote steht, ich mich vielmehr wesentlich auf die zusammenfassenden Darstellungen von Hertz. in der 1. Aufl. des Ziemssen'schen Handbuchs und von Hirsch in der 2. Aufl. seiner historisch geographischen Pathologie stützen muss, halte ich doch eine Mittheilung meiner, während eines mehr als 17 jährigen Aufenthaltes in Vera Cruz gemachten Erfahrungen nicht für überflüssig, einmal im Interesse der geographischen Pathologie und dann wegen der zum Theil noch wenig bekannten Beziehungen der Malaria zu Erkrankungen wichtiger Organe.

I. Ueber die Ostküste Mexico's als Malaria-Gebiet.

An der Bildung der Ostküste Mexico's betheiligen sich, vom Norden beginnend, der Reihe nach die Staaten Tamaulipas, Vera Cruz, Tabasco, Campeche und Yucatan, welche mit Aus- 
nahme des nördlichen, bis fast zum 26. Breitengrade reichenden Theiles von Tamaulipas, der Tropenzone angehören.

Die verticale Gliederung des Landes bedingt es bekanntlich, dass in derselben Breite alle Climate vorkommen können, ein Verhältniss, welchem durch die Unterscheidung von Tierra caliente, Tierra templada und Tierra fria Ausdruck gegeben wird. Als obere Grenze der Tierra caliente wird eine Erhebung von etwa $800 \mathrm{~m}$ über den Meeresspiegel, als solche der Tierra templada eine Erhebung von etwa $2000 \mathrm{~m}$ angenommen.

Unter "Küste" wollen wir hier den zwischen dem Meeresstrande und dem östlichen Abhange des Hochplateaus gelegenen Landstrich verstehen, unbekümmert um die sehr wechselnde Breite desselben. Im Norden bis 20 geographische Meilen von der See entfernt, nähern sich die Küsten-Anden derselben immer mehr, je weiter wir nach Süden fortschreiten, bis sie zwischen dem 19. und 20. Breitengrade mit ihren Ausläufern dieselbe fast erreichen; hierauf weichen sie wieder rasch nach Westen, bez. Süden zurück; so dass die südliche Hälfte des Staates Vera Cruz, der ganze Staat Tabasco und die dem Mexicanischen Golf benachbarten Theile der Staaten Campeche und Yucatan sich kaum über den Meeresspiegel erheben. Eine Ausnahme hiervon macht nur die Vulkangruppe des San Martin, im Canton Tuxtla, Staat Vera Cruz, welche schroff am Seeufer ansteigt. Dieser ganze, so abgegrenzte Landstrich hat das Klima der Tierra caliente und ist im Allgemeinen seiner ungünstigen Gesundheitsverhältnisse wegen verrufen. Gelbes Fieber und Malariafieber sind die unversöhnlichen Feinde nicht nur der kaukasischen, sondern auch der eingebornen indianischen Rasse und haben eine Cultivirung des meist sehr fruchtbaren Landes bis jetzt unmöglich gemacht. Das erstere herrscht freilich nur an wenigen Punkten endemisch, es ist aber sehr wahrscheinlich, dass mit Vermehrung der Communicationswege auch eine Ausdehnung seines Verbreitungsbezirks stattfinden wird, ja dieselbe hat thatsächlich bereits stattgefunden. Die Malariafieber aber sind so allgemein verbreitet, dass bei einem näheren Eingehen auf die Gesundheitsverhältnisse der einzelnen Niederlassungen immer nur von einem Mehr oder Weniger die Rede sein kann. Namentlich die dem Laufe der Flüsse folgenden sumpfigen, meist mit Wald bedeckten 
Niederungen, die zahlreichen, oft mit dem Meere communicirenden Lagunen, welche für die Ostküste Mexico's geradezu charakteristisch sind und zur Bildung eines dem Meeresstrande parallel laufenden Sumpfgürtels Veranlassung gegeben haben, sind fruchtbare Heerde für die Entwickelung der Malaria. Aber auch die waldlosen Grasebenen, die Llanos, welche in der Regenzeit überschwemmt werden, hauchen noch Monate nach dem Aufhören der Regen fiebererzeugende Miasmen aus. Ferner finden wir die Malaria in den Gebirgsthälern und Schluchten, welche die Verbindung der Küste mit dem Innern des Landes vermitteln, doch lässt sich im Allgemeinen sagen, dass mit zunebmender Erhebung über den Meeresspiegel, falls nicht locale Verhältnisse das Gegentheil bedingen, ihre Intensität and Häufigkeit abnehmen.

Gehen wir nun bei einer kurzen näheren Betrachtung unseres 400 Meilen lang ausgedehnten Malariagebietes vom Norden aus, so finden wir zwischen Matamoros am Rio bravo und Tampico am Rio Panuco eine höchst ungesunde, nur sehr schwach bevölkerte Küste; Tampico selbst ist berüchtigt wegen seiner bösartigen Malariafieber, was durch seine Lage in einer an Sümpfen und Lagunen (unter denen die nahe gelegene Laguna del carpintero die grösste ist) reichen Gegend, welche von dem Panuco und seinem Nebenflusse Tamesi durchschnitten wird, seine Erklärung findet. Gleiches gilt von Pueblo viejo de Tampico, welches dem Meere näher auf der rechten Seite des Panuco an der Lagune gleichen Namens gelegen ist, während Tampico el alto sich besserer Gesundheitsverhältnisse erfreut. Dieser kleine Ort liegt an dem nördlichen Ende der 40 Meilen langen Laguna de Tamiahua, welche durch die Boca de Santa Maleoca an ihrem südlichen Ende mit dem Rio de Tuxpam communicirt. Der Hafenort Tuxpam befindet sich nicht direct an der Mündung des Flusses, sondern 3 Leguas aufwärts; er ist ein bekannter Fieberplatz. Dasselbe gilt von den kleinen Häfen Tecolutla und Nautla, sowie von San Carlos und La Antigua Vera Cruz. Unter den mehr landeinwärts gelegenen Ortschaften der nördlichen Hälfte des Staates Vera Cruz sind als Fieberplätze Papantha und Tlapacoyan zu nennen, während das herrlich in den Bergen gelegene Misantla trotz seines heissen Klimas als ein recht gesunder Platz bezeichnet werden kann. Weiter unten 
werde ich noch Näheres über die Gesundheitsverhältnisse dieses Städtchens und dessen Umgebung anfïhren, über welche ich durch unseren Landsmann Albert Schaar, der seit 16 Jahren daselbst lebt, sehr detaillirte Angaben erhalten habe. Ein dem Europäer sehr zusagendes Klima besitzt ferner Jalapa, allerdings schon in der Tierra templada gelegen, sowie in nächster Nähe der kleine Ort Coatepec, während die Cañada de Actopan der daselbst herrschenden Malariafieber wegen der Art gefürchtet ist, dass dort gelegene grosse Haciendas verlassen worden sind. Benutzen wir die Bahn von Jalapa nach Vera Cruz, so betreten wir bei Plan del rio schon wieder die eigentliche Fieberzone: dieses sowohl, wie die folgenden Haltepunkte Puente nacional, Paso de Ovejas, Paso de San Juan Tejeria sind bekannte Fiebernester, nur der Haltepunkt La Rinconada erfrent sich eines besseren Rufes. Von Paso de Ovejas führt über die in ungesundem Terrain gelegenen Rancherias Cantaranas, Camaron und Palmita ein Weg nach der auch in weiteren Kreisen bekannten Hacienda "El Mirador", seit vielen Jahren der Sitz der allgemein geachteten Familie Sartorius, wo schon mancher europäische Reisende ein gastliches Obdach und reichliche gründliche Belehrung über die Landesverhältnisse gefunden hat. Die Hacienda selbst ist sehr gesund gelegen, höchstens kommen in der Regenzeit Fälle von leichten Intermittenten vor, dafür sind aber die im Thal gelegenen Indianerdörfer der Umgegend um so mehr von denselben heimgesucht; dasselbe gilt von dem nahe gelegenen hübschen Städtchen Huatusco.

Vera Cruz selbst ist allgemein wegen des daselbst endemisch herrschenden gelben Fiebers gefürchtet, muss aber hiervon abgesehen als einer der gesündesten Plätze der ganzen Küste bezeichnet werden. Schwere Formen von Malariafiebern sind hier nicht grade häufig und auf den südöstlichen und südlichen Theil der Stadt beschränkt, welcher den Ausdünstungen eines kleinen stagnirenden Gewässers, des sogenannten Rio Tenoyo, ausgesetzt ist. Die Beendigung der in den letzten Jahren vorgenommenen Arbeiten zur Nivellirung und Trockenlegung der nächsten Umgegend der Stadt wird sicherlich viel zur Verbesserung des Gesundheitszustandes derselben beitragen.

Die kleine Koralleninsel San Juan de Ulúa mit der für ihre 
Zeit sehr starken Festung verdient nicht unter den Hauptfieberheerden aufgeführt zu werden, wie es in dem Handbuch von Hirsch geschieht; nach den ïbereinstimmenden Berichten der Militärärzte ist der Gesundheitszustand der daselbst unter sehr ungünstigen hygieinischen Verhältnissen garnisonirenden Truppen ungleich besser, als der der Besatzung von Vera Cruz, welche grosse und reinliche Kasernen bewohnt.

Die kleine Insel Sacrificios, welche bei Hirsch ebenfalls genannt wird, liegt ganz nahe der Küste südöstlich von Vera Cruz; in den Wintermonaten, der Zeit der Nordstürme, ankern unter ihrem Schutze die Schiffe sicherer, als auf der Rhede von Vera Cruz, im Uebrigen aber ist sie unbewohnt. In der Interventionszeit diente sie als Begräbnissplatz für die französische Marine, jetzt sollen dort Quarantänegebäude errichtet werden.

Längs der Bahnstrecke von Vera Cruz bis Mexico sind als Fieberplätze $z u$ nennen das schon vorhin erwähnte Tejeria, ferner Soledad, Cameron, Paso del masho, vor Allem aber der Chiquihuite (wörtlich übersetzt Korb, so genannt, weil man sich wie am Boden eines mächtigen Korbes befindet, dessen Wände von den umgebenden Hügeln gebildet werden), ein enger Päss am Eingang in das Gebirgsland, und im Norden hiervon die viel Zucker und Kaffee producirenden Indianerdörfer Pueblo viejo und La Defensa, ferner die Station Atoyac und die Zuckerhacienda El Potrero. Auch das sonst durch angenehmes Klima sich vortheilhaft auszeichnende Städtchen Cordova und das schon viel höher, zum Theil in einem engen wasserreichen Thale gelegene Orizaba sind mit der Plage der Malariafieber und sogar in ihren schwersten Formen behaftet.

Drei Lueguas im Südosten von Vera Cruz mündet bei dem Dorfe Boca del rio der Rio de Jamapa, nachdem er sich kurz vorher mit dem Rio de Cotaxtla, demselben, welcher bei Chiquihuite unter dem Namen Atoyac aus den Bergen hervorbricht, vereinigt hat. Stromaufwärts am Rio de Jamapa liegen Medellin, Tejar, beide in der Regenzeit sehr ungesund, ferner Jamapa, das oben erwähnte grosse Dorf La Soledad und noch weiter schon in den Bergen das Städtchen Huatusco. Am Rio de Cotaxtla treffen wir zunächst die grosse Hacienda "Paso del Toro", ferner das Indianerdorf Cotaxtla, welches wegen seiner Lage auf 
steinigem Grunde sich sehr günstiger Gesundheitsverhältnisse erfreut, ebenso wie das vier Leguas weiter aufwärts liegende Indianerdorf San Jago Huatusco, während San Juan de la Punta wieder als echtes Fiebernest bekannt ist. Noch weiter in den Bergen liegt San Lorenzo, La Peñuda, ferner das grosse Indianerdorf Amatlan und schliesslich das uns schon bekannte Cordova.

Kehren wir wieder zurück nach Boca del Rio, so finden wir an dem rechten Flussufer einen Verbindungsarm zu den drei grossen, hinter einander liegenden Lagunas de Mandinga, welche sich parallel mit dem Meeresstrande bis in die Nähe von Alvarado erstrecken. Dieser für die Geschichte des gelben Fiebers in letzter Zeit so interessant gewordene Hafenort liegt an der gemeinschaftlichen Mündung dreier grosser, sich kurz vorher vereinigender Flüsse, des Rio blanco, Rio Papaloapam und Rio San Juan, welche die weite, zwischen der Sierra de Oaxaca und dem Meere gelegene Ebene durchfliessen, eine Ebene die nur zum kleineren Theile bewaldet, fast ganz von sogenannten Llanos gebildet wird. Die jährlich stattfindenden Ueberschwemmungen mächen dies ganze Gebiet für den grösseren Theil des Jahres zu einem höchst ungesunden und deshalb auch nur sehr schwach bevölkertem. Die nennenswerthesten Ortschaften sind Tlaliscoyan an einem stagnirenden, mit dem Rio blanco communicirenden Gewässer gelegen, Tlacotalpam am Rio Papaloapam und weiter stromaufwärts Cosmaloapam und Tuxtepec, Paso San Juan am Rio gleichen Namens, ferner Acayucan und Jaltipan auf dem Wege nach Minatitlan. Hart an der Küste und weit in die See vorspringend erhebt sich östlich von Alvarado die Vulkangruppe von Tuxtla mit dem San Martin. Hier verdienen die bedeutende Zuckerhacienda Montepio und das Dorf Santecomapam an der Lagune gleichen Namens als auffallend gesunde Plätze genannt zu werden; das nahe an einem See gelegene Catemaco und die Städte San Andres Tuxtla und San Jago Tuxtla dagegen sind bekannte Fieberplätze.

Wir nähern uns jetzt dem ungesundesten Theile der mexicanischen Ostküste, welche die Flussgebiete des Rio Guatzacualcos, Rio Tonala und Rio Grijalva mit seinen zahlreichen Nebenflüssen, die Ufer der Laguna de Terminos und die Küste von 
Campeche bis zur Mündung des Rio Champoton umfasst. Sowohl der Isthmus von Tehuantepec, soweit er dem Staat Vera Cruz angehört, als der ganze Staat Tabasco und ein grosser Theil des Staates Campeche müssen als Prototypen von Fieberländern bezeichnet werden. Ich erinnere an die fehlgeschlagenen Colonisationsversuche auf dem Isthmus von Seiten einer französischen Compagnie im Jahre 1830 und von Seiten der mexicanischen Regierung im Jahre 1878. Die französische Colonie in Guatzacualcos nahm ein rasches Ende, indem, wie ein noch lebendes Mitglied derselben mir mittheilte, buchstäblich fast alle Colonisten innerhalb dreier Wochen von Malariafiebern hinweggeraft wurden; von der Auflösung der mexicanischen Colonie in Suchil war ich selbst Augenzeuge. Doch selbst auf dem im Allgemeinen so ungesunden Isthmus von Tehuantepec giebt es Ortschaften, welche als relativ gesunde bezeichnet werden können, worüber uns am besten eine kurze Uebersicht des Terrains, von der Mündung des Rio Guatzacualcos beginnend, belehren wird. Der kleine Hafen Guatzacualcos liegt zwei englische Meilen stromaufwärts von der Barre entfernt, auf dem linken Flussufer, er ist ein ungesunder Ort; neun engl. Meilen weiter hinauf liegt der Rancho de Paso nuevo, wo der Weg nach Tabasco führt, ein ziemlich gesunder Platz. Gegenüber auf dem anderen Flussufer, 2 Leguas von ihm entfernt, befindet sich das ebenfalls gesunde Dorf Ixhuatlan und 6 engl. Meilen nach Osten, an einen Hügel gelehnt, das Indianerdorf Moloa, berühmt als die Heimath der schönsten Indianerinnen auf dem Isthmus. Sieben Leguas von Guatzacualcos entfernt liegt hart am Fluss das mit Recht berüchtigte Minatitlan, einer der ungesundesten Plätze, in dessen unmittelbarer Nähe sich grosse Sümpfe befinden. Westlich von Minatitlan ist das Land etwas gesünder: hier treffen wir das Indianerdorf Cosoliacaque und das schon früher erwähnte Jaltipan. Stromaufwärts von Minatitlan in sechs Leguas Entfernung liegt Hidalgotitlan und 15 Leguas weiter Xuchilapam, meist Suchil genannt, beide in der Regenzeit von schweren Malariafiebern heimgesucht."

Der nun folgende Staat Tabasco ist der wasserreichste und in Folge dessen auch ungesundeste. Flussmündung folgt längः des Meeresstrandes auf Flussmündung, während das Innere vop 
einem unentwirrbaren Netz unter einander communicirender Wasserstrassen durchschnitten wird. Hart an der Grenze des Staates Vera Cruz liegt die Barra de Tonala, ihr folgt die von Santa Ana, Cupilquillo, Dos Brazos, Chiltepec, Tabasco, San Pedro y San Pablo. Der Hauptstrom führt den Namen Grijalva; seine grössten Nebenflüsse sind links der Mescalapa, rechts der Usamacinto, dessen Quellen in den Gebirgen an der Grenze von Guatemala liegen.

An der Barre des Rio Grijalva liegt der kleine, sehr ungesunde Ort La Frontera, 30 Leguas aufwärts die Hauptstadt San Juan Bautista, am Mescalapa der Ort Huimangillo. Eines gesunden Klimas erfreuen sich nur die an dem Abhange der Sierra gelegenen Orte Teapa und Pichucalco.

Im Staate Campeche treffen wir zunächst auf die Barra de la Laguna, einem der Verbindungsarme der grossen Laguna de Terminos mit dem Meere. Nach der Seeseite wird diese Lagune durch mehrere. Inseln abgeschlossen, unter denen die grösste Isla de Carmen mit dem Hafenort Carmen, meist schlechtweg Laguna genannt. In die Lagune mündet der Rio de Palizada, eigentlich nur ein Arm des gewaltigen Usumacinto. Es bleibt noch übrig, den Rio de Champoton mit dem Hafenort gleichen Namens und die Hauptstadt Campeche zu erwähnen.

Die Küste des Staates Yucatan ist noch sehr wenig bevölkert und grösstentheils ungesund; erwähnenswerth ist nur der Hafenort Sisal.

Nachdem wir hiermit unsere kurze geographische Rundschau der Ostküste Mexicos beendigt haben, können wir einen Blick auf die Bevölkerung der Küste und ihre Disposition für Malariakrankheiten je nach Rasse und Lebensweise werfen.

II. Einfluss der Rasse und der Lebensweise auf die Disposition zu Erkrankung an Malaria.

Unter der Bevölkerung der Ostküste Mexicos finden wir 3 Rassen vertreten: die eingeborne indianische, die kaukasische und die äthiopische; aus der mannichfachen Kreuzung dieser Haupttypen ist eine sehr grosse Anzahl Untertypen hervorgegangen, unter welchen bekanntlich ebenfalls drei hauptsächlich her- 
vorgehoben werden, die Mestizen, Mulatten und Zambos, welche letztere in Mexico Indios lobos heissen.

Die reine indianische Rasse ist an der Küste fast ganz von den Mischlingen verdrängt worden; vor der europäischen Civilisation fliehend, haben sicb die Indianer von der Umgebung grösserer Niederlassungen zurückgezogen und leben meist noch unter der Herrschaft einzelner Oberhäupter, zu oft grossen Gemeinden vereinigt, in den Thälern an den Abhängen des Hochplateaus, wohin ihnen der Weisse bis jetzt nur selten gefolgt ist. Erst in den letzten Jahren hat die Landesregierung an einigen Punkten den Versuch gemacht, diese widerstrebenden Elemente zur Unterordnung und Theilnahme an den allgemeinen Interessen des Landes zu zwingen, freilich bisher mit geringem Erfolge. Geht doch die Abneigung des Indianers gegen jedes fremde Element so weit, dass er selbst dann, wenn er durch Arbeitsamkeit zu Wohlstand gekommen ist und aus Interesse den Handelsverkehr mit den Weissen sucht, jede Einmischung derselben in die Organisation seiner Gemeinde und Familie energisch und nöthigenfalls mit Gewalt zurückweist. Ein lehrreiches Beispiel für diese Starrheit des indianischen Charakters giebt das durch Kaffeecultur bekannte und reiche Indianerdorf Amatlan, welches, nur 2 Leguas von Cordova entfernt, doch einen Staat im Staate bildet. In der Ebene finden sich nur wenige, von reinen Indianern bewohnte Dörfer, von denen einige oben namhaft gemacht worden sind.

Ueber die Gesundheitsverhältnisse der rein indianischen Niederlassungen ist nur wenig bekannt. Die Sterblichkeit unter den Kindern ist allgemein eine sehr grosse; epidemische Krankheiten, wie Typhus, Blattern und auch gelbes Fieber, richten häufig grosse Verheerungen an. Wenn der Indianer, von der Noth getrieben, seine gewohnten Verhältnisse verlässt und sich zur Arbeit im Felde oder zu Eisenbahnbauten verdingt, widersteht er den Einflüsșen des Klimas entschieden schlechter, als die Mischlingsrassen oder der acclimatisirte Weisse, was zum Theil durch seine schwache Constitution, zum Theil durch seine unzweckmässige Lebensweise bedingt wird. Herr Albert Schaar in Misantla hat mir z. B. mitgetheilt, dass die indianischen Feldarbeiter daselbst ausserordentlich häufig 
an Malariafiebern erkranken und leicht dem Malariasiechthum verfallen, während eine Anzahl deutscher Familien sich bei har-

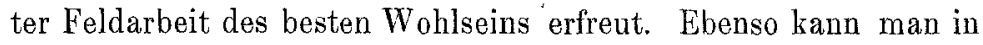
dem Hospital von San Sebastian in Vera Cruz leicht constatiren, dass der Indianer der Küste im Allgemeinen von schwacher anämischer Constitution und sehr zu Erkrankung an Malaria geneigt ist.

Die schwarze Rasse hat sich nur zum geringsten Theile rein erhalten. Sie bewährt auch in Mexico ihren Ruf der Widerstandsfähigkeit gegen klimatische Einflüsse. Wir finden den Neger entweder als Lastträger in den Städten oder als Feldarbeiter, namentlich da, wo Zuckerrohr cultivirt wird; einzelne Niederlassungen, wie Jamapa, San Carlos, Nautla, werden fast ausschliesslich von Negern und von ihnen stammenden Mischlingen bewohnt.

Die kaukasische Rasse wird fast ausschliesslich durch die Fremden repräsentirt, unter denen die Spanier an Zahl bedeutend überwiegen, dann folgen Franzosen, Deutsche, Italiener; in neuester Zeit fängt auch das nordamerikanische Element an Geltung zu gewinnen.

Die weissen Mexicaner sind mit wenigen Ausnahmen Mischlinge: das indianische Blut wiegt vor, doch ist eine Beimischung von afrikanischem Blut, sogar in den sogenannten besseren Ständen, durchaus keine Seltenheit.

Der Kern der Landbevölkerung besteht, wie schon gesagt, aus Mischlingen in den verschiedensten Abstufungen; unter ihnen sind die sogenannten Jarochos der Ostküste Mexico's mit Ausnahme des Staates Yucatan eigenthümlich. Ein Jarocho (von jaro, einem Wort arabischen Stammes, was eigentlich eine besondere rothgelbe Farbe der Schweine bedeutet) ist ein kleiner Landbesitzer, ein Ranchero, mehr Neger als Indianer, der Ackerbau and Viehzucht treibt, wenn er gerade dazu aufgelegt ist, ein Kauderwelsch von Alt-Andalusisch spricht und es allen übrigen Mischlingen trotz seines kräftigen Körperbaues an Faulheit und Nichtsnutzigkeit zuvorthut.

Unter der Mestizenbevölkerung, die im Allgemeinen kräftiger gebaut ist, als der Indianer, giebt es viele tüchtige und intelligente Elemente, welche in einem geordneten Staatsleben ihren Platz vortrefflich ausfüllen würden, aber bei dem Zustande von Willkürherrschaft und Rechtlosigkeit, wie er in Mexico seit der 
Unabhängigkeitserklärung herrscht, bei der hieraus sich ergebenden vollkommenen Confusion der Begriffe von Recht und Lnrecht, bei der bodenlosen immer wehr um sich greifenden Corruption der herrschenden Klassen, nicht zar Geltung kommen und daher in einen schlaffen Indifferentismus verfallen sind, welcher den Fremden leicht gegen ihre unleugbaren guten Eigenschaften blind macht.

Doch kehren wir nach diesem Hinweis auf die moralischen Krankheiten unserer Bevölkerung, welche das Bild der physischen zweifellos beeinflussen, zu unserem Hauptthema zurück, so muss nochmals betont werden, dass der Weisse, wenn er erst im heissen Klima zu leben gelernt hat, besser den Einflüssen desselben widersteht, als der Indianer und alle Mischlingsrassen. Hierdurch werden wir zur Betrachtung des Einflusses gefübrt, welchen die Lebensweise auf die Disposition zu Malariakrankheiten ausübt. In erster Linie kommen Wohnung, Nahrung und Kleidung in Betracht.

Dass unter gleichen klimatischen Verhältnissen Malariakrankheiten in Städten bedentend seltener sind, als auf dem Lande, fällt bei der oberfiächlichsten. Betrachtung auf, und wenn auch mancherlei andere Umstände hierzu beitragen mögen, so ist die Art zu wohnen hierbei gewiss das vorzugsweise bestimmende Element. Die Entfernung der Vegetation, die Sorge für den regelmässigen Abfluss des Regenwassers und der Unreinigkeiten, die Erhebung der Häuser über den Boden und die Art des Baumaterials schaffen in Städten günstigere hygieinische Bedingungen als in ländlichen Niederlassungen. Steinerne Hänser sind begreiflicher Weise gesünder als Holzhäuser und Rohrhütten mit Palmendächern, eine Wohnung im ersten Stock ist gesünder als eine zu ebener Erde, und Häuser auf erhöhten Punkten sichern selbst in den verrufensten Malariagegenden, wie in Minatitlan, San Juan Bautista, gegen die Infection.

Von nicht geringerer Bedeutung ist die Nahrung. Nichts erhölst unter sonst gleichen Umständen so sehr die Disposition zu Malariakrankheiten, als schlechte Ernährung, und hierauf beruht zum grossen Theil die geringe Widerstandskraft des Indianers. Fleiseh, Wein und Bier, selbst Branntwein in mässigen Quantitäten, sind im tropischen Klima nothwendige Erfordernisse 


\section{8}

und in der Hand des Arztes ebenso wichtige Heilmittel, wie Chinin und Eisen. Der unverdorbene Eingeborene ist im Essen und Trinken bedeutend mässiger als der Weisse, dafür sind seine körperlichen Leistungen aber auch bedeutend geringer, namentlich was die Energie derselben betrifft; auch in geistigen Arbeiten fehlt ihm Ausdauer und Spannkraft.

Die Bedeutnng der Kleidung erhellt aus der.Thatsache, dass im tropischen Klima die Empfindlichkeit der Hautnerven in Folge der hohen z̈usseren Temperatur unvergleichlich grösser ist als in kühleren Breiten, dass somit selbst geringe Temperaturwechsel viel mehr empfunden werden und die Disposition zu Erkältungen gesteigert ist. Unter den Gelegenheitsursachen für den Ausbruch von Malariaaffectionen nehmen aber bekanntlich Erkältungen eine hervorragende Stelle ein. Der weichliche Eingeborene schützt sich sorgfältiger als der Fremde, welcher oft sehr za seinern Schaden seine Ideen über Abhärtung des Körpers auch im heissen Klima realisiren will. Geradezu lächerlich erscheint anfangs dem Nordländer die Furcht des Mestizen vor der Morgenfrische, vor dem Nachtthau und vor der geringsten Durchnässung; bei längerer Erfahrung aber lernt er den peinlichen Schutz gegen Temperaturwechsel als eine der nothwendigsten Vorsichtsmaassregeln gegen Erkrankung an Malaria schätzen. Jedem Fremden ist das Tragen von Unterzeug, bei Neigung zu Verdauungsbeschwerden auch einer Jeichten Bauchbinde, anzurathen. Von nicht zu unterschätzender Bedeutung ist ferner die Beschaffenheit der Lagerstätte und des Schlafraums. Der Indianer, der dienende Mestize, welcher auf dem Boden schläft, wobei eine elende Strohmatte zur Unterlage dient, erkrankt begreiflicher Weise leichter, als diejenigen seiner Landsleute, welche sich den Luxus eines sogenannten Catre (Art leichten Feldbetts) erlauben können, aber selbst diese für das heisse Klima wie geschaffen scheinende Lagerstätte muss ich als ungenügend bezeichnen, falls nicht wollene Decken oder am besten Matratzen zur Unterlage angewendet werden. Die Schlafzimmer werden des Nachts selbst in den heissesten Monaten am besten geschlossen, um den Einfluss einer im ruhenden schlafenden Zustande des Körpers erfahrungsgemäss besonders nachtheiligen plötzlichen Temperaturerniedrigung abzu- 
schwächen. Meine langjährige Erfahrung berechtigt mich den Satz auszusprechen, dass bei weitem die Mehrzahl der Erkrankungen an Malariafiebern selbstverschuldete sind. Wer kräftig, aber mässig isst und trinkt, in einem trockenen Hause und nicht zu ebener Erde wohnt, ein gutes Bett hat und dem verzeihlichen Wunsch nach Abkühlung den nothwendigen $Z$ wang anzulegen weiss, der kann dreist dem Einflusse der Malaria trotzen, wenigstens was den Ausbruch acuter Infectionserscheinungen betrifft.

Nicht nur seiner im Allgemeinen kräftigen Constitution, sondern vorzüglich seiner rationelleren Lebensweise verdankt der Fremde seine in den Städten besonders auffallende grössere Widerstandsfähigkeit gegen Erkrankungen. Freilich kommt hierbei noch ein anderes Moment in Betracht, die Art der Beschäftigung, über deren Einfluss auf die Gesundheit wir jetzt kurz handeln wollen.

Die Mehrzahl aller Fremden in den Küstenstädten sind Kaufleute, welche gut leben und sich nor wenig körperlichen Anstrengungen, besonders nicht in der Sonnenbitze, auszusetzen haben. Wie steht es aber mit der Befähigung des Weissen, bez. des Nordländers zum Ackerbau in tropischen Klimaten? Die unglüeklichen Resultate mehrfacher Colonisationsversuche scheinen auf den ersten Blick diese Befähigung vollkommen in Abrède zu stellen; meine Ueberzeugung aber ist, dass diese Resultate vielmehr der völlig planlosen und unvernünftigen Weise, europäische oder nordamerikanische Emigranten einzuführen, als deren Untauglichkeit zu verdanken sind. Vor einer Immigration im grösseren Maassstabe auf einmal möchte ich entschieden warnen, weil dann die Unterbringung der Colonisten und ihre Verpflegung mit $z u$ grossen Schwierigkeiten verknüpft ist; ich möchte vielmehr zur Gründung von Colonien von kleinen Anfängen aus, höchstens 20-30 Familien, rathen.

Die Terrains müssen Eigenthum der Colonisten und von sachverständigen und, was die Hauptsache, ehrenhaften Lnternehmern ausgesucht sein; auf die Lage der Colonie in der Nähe einer Verkehrstrasse, wo möglich Eisenbahn, und einer schon bestehenden grösseren Niederlassung ist grosses Gewicht zu legen. Die Häuser, am besten Steinhäuser, müssen vorher gebant und im wohnlichen Zustande sein; auf keinen Fall dürfen die Colo- 
nisten später als im Monat November eintreffen, um die nothwendigen Erdarbeiten und Urbarmachungen noch in der kühleren Jahreszeit ausfübren za können, und sie müssen bei diesen Arbeiten von gedungenen eingeborenen Feldarbeitern unterstützt und unterwiesen werden. Ein recht ermuthigendes Beispiel für die Möglichkeit der Gründung europäischer Colonien selbst in den heissesten Küstengegenden liefern die im Anfang der dreissiger Jahre gegründeten französischen Colonien Jicaltepec und Zopilotes, die erstere auf dem rechten, die letztere auf dem linken Ufer des Rio de Nautla, 4 Leguas weit von der Mündung gelegen. Diese jetzt etwa $800 \mathrm{Köpfe} \mathrm{starke} \mathrm{Niederlassung} \mathrm{befindet} \mathrm{sich,}$ freilich nach einer Reihe von Wechselfällen und nach zweimaliger Invasion durch das gelbe Fieber, heute im blühenden Zustande, besonders seit die Colonisten nicht mehr Pächter, sondern Herren ihres Terrains geworden sind. Erst seit wenigen Jahren hat die mexicanische Regierung den für die Zukunft des Landes entscheidenden Schritt gethan, die früheren Gemeindegüter unter die einzelnen Gemeindemitglieder zu vertheilen; erst hierdurch ist es dem nationalisirten Fremden möglich geworden, Ländereien eigenthümlich zu erwerben.

Dass die bisher grösstentheils noch unzugänglichen Waldregionen der Tierra templada ein ungleich günstigeres Terrain für Colonisation abgeben, als die heissen Küstenebenen, liegt auf der Hand. Ich habe das Beispiel von Jicaltepec nur angeführt, um $z u$ beweisen, dass die weisse Rasse auch unter ungünstigen klimatischen Verbältnissen prosperiren kann und dass ihre körperliche und geistige Ueberlegenheit auch anfangs unüberwindlich scheinende Schwierigkeiten bewältigen lernt.

III. Ueber Acclimatisation in Bezug auf Malaria.

Unter allen acuten Infectionskrankheiten giebt es kaum eine zweite, welche wie die Malariainfection in innigster Beziehung zu dem Klima, d. h der geographischen Breite, den Witterungsverhältnissen, der Vegetation, dem Feuchtigkeitsgrade und der Bodenbeschaffenheit einer Gegend steht, und bei welcher der Begriff Acclimatisation eine so zutreffende Anwendung finden sollte, als bei dieser. Nach der gewöhnlichen Fassung jenes Begriffes ist dies aber durchaus nicht der Fall, denn im Allge- 
meinen wird die Widerstandsfähigkeit des Individuums gegen Malaria durch ïberstandene Anfälle nicht erhöht, sondern geschwächt. Versteht man aber unter Acclimatisation nicht den erworbenen Zustand des Organismus, gegen gewisse Schädlichkeiten immun zu sein, sondern die erworbene Fähigkeit des Individuums, seine Lebensweise den klimatischen Verhältnissen eines Ortes anzupassen und sich so gegen Schädlichkeiten zu schützen, dann findet dieser Begriff mit vollstem Rechte Anwendung auf die Malariakrankheiten. Ein Nordländer, welcher drei Tage nach seiner Ankunft in Vera Cruz am gelben Fieber erkrankt, jst mit absoluter Sicherheit immun gegen diese Krankheit, so lange er im Bereiche derselben verweilt, ja er ist in bei weitem den meisten Fällen überhaupt unempfänglich für das Virus des gelben Fiebers geworden, und doch kann man unmöglich sagen, er sei acclimatisirt, wie dies unrichtiger Weise von vielen Seiten geschieht. Man muss eben solche Infectionskrankheiten, deren einmaliges Ueberstehen Immunität, und zwar absolute oder relative, bedingt, unterscheiden von anderen, gegen welche das Individuum sich nur durch Anpassung der Lebensweise schützen lernt. Impfschutz und Acclimatisation sind zwei vollkommen verschiedene Begriffe und müssen in der Lehre der acuten Infectionskrankheiten strenger auseinandergehalten werden, als dies bisher geschehen ist.

Ob im Laufe von Generationen durch Erliegen der schwächeren und Ueberleben der kräftigeren Elemente die Bewobner von Malariadistricten eine relative Immunität gegen die Krankheit erwerben können. ist eine ganz andere und wie ich glaube bei dem heutigen Stande der historischen Pathologie nicht zu entscheidende Frage; dass aber die Disposition nicht nur der verschiedenen Rassen, sondern auch der Individuen einer Rasse für die Krankheit eine ausserordentlich verschiedene ist, muss als Thatsache anerkannt werden. Wenn Hirsch die geringe Disposition der äthiopischen Rasse für Malariakrankheiten als eine erworbene hinstellt und zur Erklärung derselben auf die grosse Sterblichkeit unter den Kindern hinweist, kann man ihm mit Recht erwidern, dass dieselbe grosse Kindersterblichkeit auch unter den reinen Indianern und Mischlingen in Mexico beobachtet wird, ohne dass deshalb der erwachsene Indianer oder 
Mestize dieselbe Widerstandsfähigkeit besitzt, wie der mit ihm unter gleichen Verhältnissen lebende Neger oder Zambo. Der Mulatte ist meinen Erfahrungen nach schon viel mehr der Malariainfection ausgesetzt, als der reine Neger oder Zambo. Unter den in Vera Cruz lebenden Fremden, beispielsweise unter unseren Landsleuten, kenne ich eine ganze Anzahl, welche nie an Malariafiebern litten, während andere von vornherein eine so ausgesprochene Disposition für dieselben mitgebracht haben, dass sie sich fast nie eines vollkommenen Wohlseins orfreuen.

IV. Ueber den Einfluss der Jahreszeit und der Witterung auf die Häufigkeit und Schwere der Erkrankungen an Malaria.

In Vera Cruz - nur von diesem Punkte der Ostküste Mexico's steht mir eine hinreichende Erfahrung zu Gebote - herrschen Malariakrankheiten zu allen Jahreszeiten, erreichen aber zweimal im Jahre ein Maximum, beim Beginn der Regenzeit und nach dem Aufhören derselben, Termine, welche erheblichen Schwankungen unterworfen sind. Die regelmässigen Regen beginnen in Vera Cruz meist Ende Juni und dauern bis gegen Ende October mit einer mehr oder minder ausgeprägten Pause während der Hundstage. In anderen seltneren Jahren beginnen die Regen früher, schon im Monat Mai, ja selbst im März fallen mitunter schon starke Regengüsse, wie dies im Jahre 1849 der Fall war; diesen vorzeitigen Regen folgt eine Zeit der Trockenheit bis zum Eintritt der gewöhnlichen Regenzeit; diese Jahre sind es, welche sich durch Häufigkeit der Erkrankungen an Malaria und durch die Schwere derselben auszeichnen. Das Ende der Regenzeit ist meist ein sehr markirtes; seltener wird dasselbe hinausgeschoben, sogar, wie im vorigen Jahre, bis Ende November.

Im Allgemeinen fallen die leichteren Formen von Malariainfection auf den Anfang der Regenzeit, während die Monate October bis Januar sich durch schwere Fórmen auszeichnen; ausgenommen sind die eben erwähnten Jahre mit vorzeitigem und unregelmässigem Regenfall, in denen schon von Anfang an schwere Formen aufzutreten pflegen.

Trockene und heisse Jahre, wie das laufende, sind in Vera 
Cruz die gesundesten, feuchte mit häufig wechselnder Temperatur die ungesundesten.

Interessant ist, was den Einfluss der Jahreszeit und Witterung betrifft, eine Vergleichung der Malariafieber mit dem gelben Fieber. Während die ersteren in unleugbarer innigster Beziehung zu dem Grade der Durchfeuchtung des Bodens und zu Temperaturwechseln stehen, ist ein solcher Einfluss dieser Momente auf die Erkrankungen an gelbem Fieber durchaus nicht mit Sicherheit nachzuweisen. Diese Krankheit spottet vielmehr aller theoretischen Betrachtungen, die sich in dieser Richtung anstellen lassen und die namentlich im Laienpublikum mit so vieler Vorliebe angestellt werden.

V. Ueber die verschiedenen Formen der Malariainfection.

Wenn auch in einzelnen Gegenden Europas recht mannichfache und schwere Formen der Malariakrankheiten vorkommen, lernt doch die Mehrzahl der europäischen Aerzte aus eigener Erfahrung nur wenig von denselben kennen. Auch die in den besten Handbüchern gegebenen Darstellungen lassen fühlbare Lücken, namentlich was die Beziehungen der Malariainfection zu Erkrankungen der Lungen, des Herzens, der Leber und der Nieren betrifft.

Die heissen Küstenstriche der Tropenländer sind die ergiebigsten Pflanzstätten der Malaria, wenn wir diesen Collectivbegriff festhalten wollen; hier überwiegen die durch sie hervorgebrachten Krankheiten über alle ïbrigen so sehr; dass man sie unbedenklich an die Spitze einer Betrachtung der Gesundheitsverhältnisse jener Gegenden stellen muss. Welches Feld der Forschung noch auf diesem Gebiete zu bearbeiten bleibt, kann nur der Arzt ahnen, welcher wie ich eine lange Reihe von Jahren in tropischen Malariadistricten gelebt hat. Wenn das wenige Neue, was ich in den folgenden Zeilen dem Leser bieten kann, dazu beitragen sollte, das Interesse der Fachgenossen auf diesen theoretisch und praktisch gleich wichtigen Gegenstand zu lenken, so werde ich mich entschädigt fühlen für das schmerzende Bewusstsein, in meiner Stellung als praktischer Arzt weder Zeit noch Mittel gehabt zu haben, die hier einschlägigen Studien mit der nöthigen Consequenz zu verfolgen. 
1. Einfache intermittirende Fieber.

Auch für Vera Cruz kann ich die in anderen tropischen Ländern gemachte Erfahrung bestätigen, dass die intermittirenden Fieber mit Quotidiantypus die häufigsten sind; ich muss aber hervorheben, dass ich im Laufe der Jahre doch auch eine ganz hübsche Reihe ron Fällen mit Quartantypus beobachtet habe. Vom Quotidian- zum remittirenden Typus finden sich Uebergänge in allen Abstufungen, so dass an der Einheit des zu Grunde liegenden Krankheitsprozesses nicht gezweifelt werden kann; wohl aber bin ich der Ansicht, dass ein grosser Theil der sogenannten schweren remittirenden Fieber von den Malariakrankheiten abgetrennt werden muss. Die Gründe dafür sollen weiter unten dargelegt werden.

Das einfache intermittirende Fieber tritt in so mannichfaltigen Modificationen, je nach dem wahrscheinlichen Ausgangspunkt und dem Grade der Infection und je nach der Disposition des Individuums auf, dass eine erschöpfende Darstellung kaum zu geben sein würde; es sollen hier vielmehr nur einige Hauptformen hervorgehoben werden, wobei das einfache, ohne besonders hervorstechende Localsymptome verlaufende Fieber aus naheliegenden Gründen ausgeschlossen bleibt.

a) Die katarrhalische Form des einfachen Wechselfiebers mit Quotidiantypus ist in Vera Cruz ausserordentlich häufig: Schnupfen mit starker Reizung der Conjunctiven, Bronchialkatarrh, oft mit hochgradiger Dyspnoe, charakterisiren diese Form, zu welcher sich mit Vorliebe Neuralgien im Gebiet des Quintus oder des Plexus cervicalis hinzugesellen. Die Intermissionen sind in einer Reihe von Fällen sehr scharf ausgeprägt, in anderen nur unvollkommen, so dass die Affection von einer gewöhnlichen fieberhaft katarrhalischen nicht unterschieden werden kann. Aus diesem. Grunde behandle ich seit einer Reihe von Jahren jeden, selbst nur leicht fieberhaften Bronchialkatarrh oder starken Schnupfen mit Chinin und kann diese Behandlung als ausserordentlich wirksam empfehlen. Auch bei epidemischen Bronchialkatarrhen (Grippe) habe ich von der Chininbehaudlung die besten Erfolge gesehen.

Weniger häufig, aber von schwereren Symptomen begleitet ist 
b) die gastrische Form. Magenschmerzen von oft unerträglicher Heftigkeit, qualvolles und schwer zu stillendes Erbrechen, kurz die Symptome eines acuten Magenkatarrhs begleiten das, meist sehr deutliche Intermissionen zeigende Fieber. Diese Form wird vorzugsweise in Jahren beobachtet, in welchen auch andere schwerere Malariaaffectionen häufig sind. Hieran schliesst sich

c) die gutartige diarrhoische und die viel schwerere cholerische Form, welche leicht einen gefahrdrohenden Charakter annimunt und daher in der Mehrzahl der Fälle den perniciösen Fiebern zugezählt werden muss.

d) die dysenterische Form ist nicht so selten, als ich nach den Erfahrungen der ersten Jahre meines Aufenthalts in Vera Cruz glaubte; sie ist vorzugsweise dem jugendlichen Alter eigen, befällt aber auch Erwachsene. Ihre grosse" Wiohtigkeit für die Entstehung von Leberabscessen werden wir später besprechen.

e) Selten, aber sehr interessant ist eine Form des Quotidianfiebers, welche mit deutlich intermittirenden, oft ausserordentlich heftigen Kolikanfällen und mit hartuäckiger Verstopfung einhergeht. Vor einer Verwechslung mit der in das Gebiet der chronischen Bleivergiftung gehörigen sogenannten "Colique sèche" schützt vor Allem der fieberhafte und deutlich intermittirende Charakter dieser Affection. Dem Anfänger in der Kenntniss von der proteusartigen Natur der Malariakrankheiten pflegen diese Fälle nicht geringe Verlegenheiten zu bereiten, da derselbe, getäuscht durch die hervorstechenden Symptome, den oft bis zum Unerträg]ichen gesteigerten Schmerz und die Verstopfung, sich veranlasst fühlt, zunächst Klystiere und innere Abführmittel in allen möglichen Formen oder zur momentanen Linderung der Qualen seines Kranken Narcotica zu appliciren, aber zu seinem Erstaunen sich von der völligen Erfolglosigkeit seines scheinbar durchaus rationellen Verfahrens überzeugen muss, während einige mittlere Gaben Chinin die Kolikanfälle mit Leichtigkeit beseitigen und die gewünschten Darmentleerungen auch ohne Hülfe von Abführmitteln herbeiführen.

Nach meinen Erfahrungen muss ich das Vorkommen einer Malariaaffection, deren am meisten auffallende Symptome Kolik- 
schmerzen und Verstopfung sind, auf das Bestimmteste behaupten, und die diagnostischen Irrthümer anderer Autoren, welche Fälle von Bleikolik für ein eigenthümliches, endemisch vorkommendes Leiden angesehen haben, können mich daran nicht irre machen. Es liegt in der That auch gar nichts Auffallendes darin, dass in einer Krankheit, wie die Malariainfection, welche alle möglichen nervösen Apparate afficirt und zu den heftigsten Neuralgien Veranlassung giebt, gelegentiich auch einmal die Darmnerven in hervorragender Weise betheiligt werden.

Ich bin also weit davon entfernt, von einer endemischen Colique tropicale zu sprechen, sondern constatire einfach das, wenn auch seltene, Vorkommen von heftigen Kolikanfällen als ein Glied in der langen Symptomenkette der Malariainfection.

f) Biliöse Form. Der Ausdruck "biliöses Fieber" wird von den Autoren über Tropenkrankheiten vielfach in so wenig bestimmter Weise gebraucht, dass es nothwendig erscheint, sich vorher über diesen Begriff zu.verständigen. Wenn eine einfache Malariaaffection sich, wie so häufig, mit Magen-Darmkatarrh und in Folge dessen auch mit Icterus combinirt oder wenn reichliche Mengen Galle erbrochen werden, so rechtfertigt dies, wie ich glaube, keineswegs die Aufstellung einer besonderen Kategorie von Fiebern, höchstens könnte man von einer icterischen Form der Nalariafieber sprechen. Ein anderes aber ist es, wenn die Leber in directer Weise sich an dem Krankheitsprozess betheiligt und die Symptome einer activen Fluxion den Icterus begleiten. Freilich wäre es wohl richtiger, in diesen Fällen von einer Forma hepatica der Malariafieber zu sprechen und die Bezeichnung "biliöse" auf diejenigen, mit den Erscheinungen des Icterus gravis einhergehenden Fieber zu beschränken, in denen wir Grund haben, eine durch massenhaften Zerfall von rothen Blutkörperchen bedingte abnorme Anhäufung von Gallenfarbstoffen im Blut, oder kurz gesagt, einen hämatogenen Icterus anzunehmen. Die Besprechung dieser Fieber gehört in das Kapitel über schwere Malariaaffectionen. Hier soll nur von der Forma hepatica der leichteren Grade derselben, welche wir dem Sprachgebrauch zu Liebe "leichtes biliöses Malariafieber" nennen wollen, die Rede zein.

In Vera Cruz sind diese Fälle nicht gerade häufig, auch 
seheint mir eine besondere individuelle Disposition nothwendig zu sein, damit ein einfaches Wechselfieber, selbst wenn die Symptome desselben einen hohen Grad von Intensität erreichen, sich mit einer activen Congestion zur Leber combinire. Hierfür spricht ausser dem relativ seltenen Vorkommen die Erfahrung, dass die betreffenden Individuen diese Erscheinung in der Regel bei jedem Wechselfieberanfall, selbst dem leichtesten, zeigen. Unmässigkeit im Alkoholgenuss spielt zwar eine Rolle als Gelegenheitsursache, darf aber nicht in erster Linie angeschuldigt werden, da auch sehr mässig lebende Individuen von dieser Affection befallen werden, während notorische Trinker sich oft eine lange Reihe von Jahren hindurch des besten Wohlseins erfreuen oder von, zur Cirrhose führender, chronischer Hepatitis ergriffen werden. Wo freilich Disposition für Fluxionen nach der Leber vorhanden ist, da genügt oft der geringste Excess, um dieselben herbeizuführen, so dass ich mich mehrmals genöthigt gesehen habe, derartigen Kranken den täglichen Genuss auch nur eines Glases Bier zu untersagen. Dass im Allgemeinen in den Tropen Alkoholmissbrauch viel längere Zeit ohne schädliche Folgen ertragen wird, als im kalten Klima, geht aus meinen Erfahrungen zweifellos hervor; dass ferner ein mässiger Alkoholgenuss in den meisten Fällen und speciell bei Neigung zu Malariafiebern vortheilhaft wirkt, ist eine anerkannte Thatsache, aber umgekehrt giebt es Individuen, bei denen jede Unmässigkeit im Trinken die vorhandene Disposition zu Wechselfiebern erhöht, ohne dass sie jedoch deshalb auch an Lebercongestionen $\mathrm{zu}$ leiden brauchen.

Die Hepatitis malarica ist an sehr vielen Punkten der Küste ungleich häufiger als in Vera Cruz und gehört ohne Zweifel schon zu den maligneren Formen der Malariaaffectionen, da ihre Consequenzen nur allzu häufig für den Kranken verhängnissvoll werden.

Eine sehr beachtenswerthe Thatsache ist, dass Individuen, bei denen Wechselfieberanfälle sich leicht mit Leberfluxionen combiniren, häufig auch eine grosse Neigung zu Dysenterie haben, ja dass bei ihnen jeder Anfall von dysenterischen Erscheinungen begleitet wird. Ich hebe ausdrücklich hervor, dass es in den hier besprochenen Fällen sich um eine ausgesprochene 
Malariadysenterie handelt und dass wir diese Fälle sorgfältig von denen trennen müssen, wo bei Dysenterie aus anderen $\mathrm{Ur}-$ sachen sich Hepatitis und Abscessbildung in der Leber einstellen, so gross auch die Analogie im Krankheitsverlaufe bei beiden Reihen ron Fällen sein möge.

Die Hepatitis malarica weicht nach meinen Erfahrungen fast immer einer rechtzeitiger energischen Chininbehandlung, wo letztere aus Furcht vor dem schädlichen Einfluss des Chinin auf die Leber, - einer Furcht, welche leider selbst unter den hiesigen Aerzten noch sehr verbreitet ist, - unterbleibt: in sehr schweren Fällen führt sie auch trotz derselben sehr leicht zur Abscessbildung. Im Gegensatz zu der allgemein herrschenden Ansicht kann für mich und mehrere der hiesigen Collegen auch nicht der geringste Zweifel bestehen, dass ein grosser Theil der an der Ostküste Mexico's beobachteten Leberabscese einer Malariainfection seine Entstehung verdankt.

Ich werde in einem der folgenden Capitel auf diesen Gegenstand zurückkommen; hier genügt es, auf den causalen $\mathrm{Zu}$ sammenhang von Malariainfection und Leberabscess hingewiesen zu haben.

Es verdient ferner hervorgehoben zu werden, dass die Hepatitis malarica unter den Fremden durchaus nicht häufiger vorkommt, als unter den Eingebornen, dass vielmehr ihre Frequenz in directem Verhältniss zur Ungunst der hygieinischen Verhältnisse einer Ortschaft, also überhaupt zur Schwere der Malariaaffectionen an einer bestimmten Localität steht, ein Umstand, welcher ihr relativ seltenes Vorkommen in Vera Cruz erklärt. Ich habe während einer beinahe 17jährigen Praxis unter den dauernd in Vera Cruz lebenden Fremden nur wenige Fälle von Hepatitis malarica und nur 2 Fälle von Leberabscess überhaupt behandelt, von denen der eine ausschliesslich auf chronischen Alkoholmissbrauch zurückgeführt werden musste, während dieselben Affectionen unter den Eingebornen ungleich häufiger vorkommen. Ein junger Deutscher musste, um diè zuletzt wohl unvermeidliche Ausbildung eines Leberabscesses zu verhindern, wegen wiederholter Anfälle von Hepatitis malarica in seine Heimath zurückgeschickt werden. Das Hauptcontingent für diese 
Affection und ihren übelsten Ausgang, den Leberalsscess, stellen in Vera Cruz die aus verrufenen Malariadistricten, wie Tlaliscoyan, Catemaco, Minatitlan, Tabasco, zureisenden Fremden und Einheimischen.

g) Cerebrale Form. Leichtere cerebrale Erscheinungen, Coma, grosse Unruhe und Delirien begleiten, namentlich bei Kindern, häufig die Wechselfieberanfälle und drücken ihnen einen eigenthümlichen Charakter auf, aber auch bei Erwachsenen stellen sich zuweilen während des Anfalles grosse Eingenommenheit des Kopfes, Stumpfheit der Intelligenz, Unruhe und Delirien ein. Individuelle Disposition ist auch hier maassgebend.

h) Eclamptische Form. Dieselbe ist bei Kindern häufig, gestattet aber eine durchaus günstige Prognose. Bei Erwachsenen habe ich Convulsionen während des Anfalles nur selten beobachtet.

i) Nervöses Herzklopfen bildet nicht gerade selten eines der am meisten hervorstechenden und den Kranken am meisten beunruhigenden Symptome eines Anfalls.

k) Die schleichende, nicht in bestimmt markirten Anfällen auftretende, sondern mehr durch unbestimmtes allgemeines Unbehagen, Gliederschwäche, vage Schmerzen, Ohrensausen u. s.w. charakterisirte Form des Wechselfiebers, welche Hertz beschreibt, ist auch in Vera Cruz sehr häufig, aber nicht allein als Zeichen der chronischen Infection, sondern auch bei frischen Ankömmlingen. Ich weise stets meine Klienten an, auf die Farbe ihres Urins zu achten; abnorme Rötbung desselben, auch wenn eine Erhöhung der Körpertemperatur ohne weiteres nicht wahrzunehmen jst, lässt mit Sicherheit auf Fieber schliessen.

Eiweiss im Urin wird auch bei einfachen Malariafiebern zuweilen beobachtet; von der Nephritis malarica wird weiter unten die Rede sein.

\section{Larvirte Wechselfieber.}

Von den sogenannten larvirten Wechselfiebern sollen hier nur die typischen Neuralgien berücksichtigt werden; die übrigen hierher gerechneten Formen finden in anderen Capiteln ihre Erledigung. In Vera Cruz sind typische Neuralgien ungemein häufig und glaube ich nicht febl zu greifen, wenn ich die so 
allgemein, sowohl unter Fremden, als Einheimischen, verbreitete Anämie als Ursache dieser Erscheinung anschuldige. Ihren Charakter als larvirte Fieber bewahren übrigens diese Nêuralgien nur in sehr seltenen Fällen, meist sind sie von deutlichen, bei einzelnen Formen sogar heftigen Fiebererscheinungen begleitet; oft auch stellen sie sich ein, nachdem die eigentlichen Fieberanfälle aufgehört haben, oder gehen umgekehrt denselben voraus.

Am häufigsten sind, wie aller Orten, so auch in Vera Cruz die Neuralgien im Gebiete des Quintus, fast eben so häufig die im Bereich des Plexus cervicalis, schon viel seltener reine Intercostalneuralgien und am seltensten Neuralgien des Plexus ischiadicus.

Erwähnenswerth scheint mir ein Fall von Supraorbitalneuralgie bei einem kräftigen jungen Manne, weil hier jedem Schmerzanfall eine 10-15 Minuten dauernde absolute Verdunklung des Gesichts vorausging (Amaurosis intermittens). Leider faud ich nicht Gelegenheit, während des Anfalles die Augenspiegeluntersuchung vorzunehmen.

Auffallend häufig, namentlich bei dem weiblichen Geschlecht, kommt die schon von Fallot und Peter, allerdings nicht als Manifestation der Malaria, beschriebene Neuralgia phrenica vor. Diese Affection ist immer von starkem Fieber begleitet und wohl geeignet, auch dem ruhigsten Kranken und selbst dem Arzt Besorgniss einzuflössen. Nachdem in der Regel einige leichtere Fieberanfälle vorausgegangen sind, stellen sich heftige Schmerzen im Bereiche der unteren Cervicalnerven, namentlich aber im Verlauf der Nervi phrenici ein, welche von den Kranken sehr richtig localisirt werden. Die Zwerchfellsathmung ist fast ganz unmöglich, nur mit den Rippen vermag der Kranke mühsam luft zu schöpfen, und er befindet sich daher in einem Zustande der qualvollsten Dyspnoe, welche noch dadurch vermehrt wird, dass auch jede Bewegung des Nackens und der oberen Extremitäten von oft unerträglichen Schmerzen begleitet wird. Das heftige Fieber, die Dyspnoe, die cyanotische Färbung des Gesichts, die Schmerzen lassen im ersten Augenblick leicht an eine schwere entzündliche Lungenaffection denken, und erst die objective Untersuchung belehrt über den wahren Sachverhalt. 
Was die Behandlung der typischen Neuralgien betrifft, so haben meine Erfahrungen ergeben, dass Chinin um so wirksamer ist, je deutlicher die Fiebererscheinungen ausgeprägt sind, während Arsenik bei reinen oder nur von unbedeutendem Fieber begleiteten Neuralgien vortrefliche Dienste leistet und umgekehrt. Den Ruf des Arseniks als Mittel gegen Malariainfection $x \alpha \tau^{\prime}$ ¿̧̇oỳv kann ich durchaus nicht bestätigen; er hat sich mir wie gesagt nur bei neuralgischen Affectionen und zwar den möglichst fieberfreien und ferner bei chronischer Infection und Malariacachexie zur Hebung der Ernährung bewährt, während er sich gegen die acute Infection und als Präservativmittel, wie ich ihn namentlich von amerikanischen Aerzten häufig anwenden sah, vollkommen wirkungslos erwies. Mehrmals habe ich weibliche Kranke, welche schon seit Monaten wegen schwerer Anämie Arsenik in hohen Dosen genommen hatten, von Wechselfieber befallen werden sehen, welches die Anwendung des Chinin nothwendig machte. Wo nach Beseitigung der heftigen Fiebererscheinungen Neuralgien zurückbleiben, ist der Arsenik vollkommen am Platz; auch die Combination von Chinin mit Eisen leistet namentlich bei anämischen Kranken zur Nachkur oft sehr gute Dienste.

\section{Perniciöse Wechselfieber.}

Es ist schwer, eine scharfe Definition des Begriffes „perniciöses Fieber“ zu geben, da unter Umständen auch ganz einfache Fieber Lebensgefahr bedingen können und die Bestimmung der Schwere eines Falles nicht frei ist von Willkürlichkeiten. Hier sollen als perniciös nur die Fieberanfälle bezeichnet werden, in denen die Symptome an und für sich, ohne Rücksicht auf besondere schon bestehende Complicationen, eine evident gefahrdrohende Intensität erreichen. Dies kann nun bei jeder der oben betrachteten Formen des Malariafiebers der Fall sein und es ist überflüssig, des näheren darauf einzugehen; hier sollen nur einige praktische Bemerkungen und die Erörterung bisher nicht erwähnter, gewöhnlich den perniciösen zugezählter Formen Platz finden.

Von grösster praktischer Wichtigkeit ist die Thatsache, dass ein intermittirendes Fieber niemals mit perniciösen Erscheinun- 
gen beginnt, sondern dass denselben stets eine Reihe leichterer Anfälle vorausgehen, dass mithin die namentlich hier in Vera Cruz verbreitete Furcht, es könne ein Individuum ohne weitere Vorboten von einem perniciösen Fieber befallen werden, vollkommen unbegründet ist. Ich habe dieser Frage besondere Aufmerksamkeit gewidmet und den eben ausgesprochenen Satz ohne Ausnahme bestätigt gefunden. Für die Praxis geht daraus hervor, dass man in berüchtigten Malariadistricten keinen Fieberanfall leicht nehmen darf, namentlich nicht bei Kindern, deren grosse Sterblichkeit wesentlich auf Nichtbeachtung der ersten leichten Fiebererscheinungen von Seiten der Angehörigen zurückzuführen ist.

Sebr deutlich ist der Einfluss der hygieinischen Verhältnisse auf die Häufigkeit perniciöser Anfälle; während ich in den gebildeteren Kreisen meiner Kundschaft in 17 Jahren nur 12 perniciöse Anfälle beobachtet habe, sind dieselben in den hiesigen Hospitälern und in den niederen Schichten der Bevölkerung (Arme in unserem Sinne giebt es hier nicht) häufig, aber lange nicht in dem Grade, wie z. B. in Tampico, Minatitlan, Tabasco.

Was die Form der Anfälle betrifft, so überwiegt bedeutend die cerebrale und die algide Form, demnächst kommt die syncopale, cholerische, und als seltenste die icterische in Betracht.

Wenig beachtet scheint mir eine Form, welche ich zweimal in epidemischer Verbreitung beobachtot habe, and welche ich die rheumatisch-hämorrhagische nènnen will.

Nach mehreren leichten stellt sich plötzlich ein ausserordentlich heftiger Fieberanfall mit ungewöhnlich verlängertem Froststadium ein; reine Galle wird in reichlicher Quantität erbrochen, der Urin ist roth, eiweissfrei. Nach dem Anfall fühlt sich der Kranke in ungewöhnlichem Grade matt und bald stellen sich reissende Schmerzen in einigen, oft in fast allen Gelenken ein, welche auch geringe Bewegungen unmöglich machen. Schon nach wenigen Stunden sind die Gelenke geschwollen, von ausgetretenem Blut blauroth gefärbt; auch Blutungen in das Unterhautgewebe, Nasen- und Darmblutungen sind häufig. Die Reconvalescenz ist eine ausserordentlich lange. Alle meine Fälle betrafen kräftige Männer, und hierin ist wohl der Grund zu suchen, dass keiner derselbon tödtlich endigte. Sollten nicht die 
leichteren Grade dieser Form von Malariafieber, bei denen es nicht zu ausgedehnten Blutungen in die Gelenke, sondern nur zu Sugillationen im Unterhautgewebe kommt, identisch sein mit dem früher als Peliosis rheumatica beschriebenen Leiden? -

Einer näheren Betrachtung sollen hier noch die Erkrankungen der Nieren, Lungen und des Herzbeutels unterzogen werden.

Nierenaffectionen bei Malariafiebern.

Dass in jedem. Wechselfieberanfall die Nierenfunction, wenn auch meist nur vorübergehend, alterirt wird, beweisen die eigenthümlichen Verhältnisse der Urinsecretion während desselben. Im Frost- und Hitzestadium ist bekanntlich die Urinabsonderung in der Regel spärlich wie bei jedem anderen Fieber und hebt sich erst wieder im Schweissstadium; in einer anderen Reihe von Fällen wird aber grade während des Fieberfrostes ein heller Urin in reichlicher Menge abgesondert, eine Erscheinung, welche doch wohl nur durch eine eigenthürnliche Wirkung auf den die Nierencirculation regulirenden nervösen Apparat erklärt werden kann, grade wie die reichliche Urinsecretion bei einem hysterischen Anfall.

Das "vorübergehende Vorkommen von Eiweiss lässt sich den heutigen Anschauungen gemäss wohl mit Recht als eine directe Wirkung der Temperatursteigerung betrachten. Andauernder Eiweissgehalt des Urins aber deutet auf ein tieferes Ergriffensein der Nieren.

Acuter Morbus Brightii bei Malariainfection wird beobachtet

1. als Theilerscheinung eines perniciösen Anfalles. Die Urinsecretion wird alsdann sehr spärlich oder stockt ganz, die kleinen entleerten Quantitäten sind trübe von ausgeschiedenen Uraten, hochroth oder dunkelbraun, enthalten reichlich Eiweiss, rothe Blutkörperchen und Harncylinder; meist ist auch Gallenfarbstoff nachzuweisen. Stellt sich die Nierenfunction nicht rasch genug wieder her, so stirbt der Kranke unter dem Bilde der Urämie (urämische Form der perniciösen Fieber).

2. in seltenen Fällen, ich habe deren nur drei beobachtet, als primäre Affection. Alle drei Fälle betrafen junge Leute, bei denen sich gleich in den ersten Fieberanfällen ungewöhnlich starke Nierenschmerzen einstellten. Die rasch sich entwickeln- 
den Oedeme, die Untersuchung des Urins konnten keinen Zweifel an der Natur des Uebels lassen. Einer der Kranken starb unter urämischen Erscheinungen, zwei genasen nach langem Krankenlager vollständig.

Eine chronische Form der Nierenentzündung, welche sich von dem gewöhnlichen chronischen Morbus Brightii durch ihre Heilbarkeit unterscheidet, findet sich als primäre Affection oder als Symptom der chronischen.

Namentlich die nicht seltenen Fälle erster Art sind interessant und praktisch wichtig, weil sie leicht zu diagnostischen und prognostischen Irrthümern Veranlassung geben. Die Kranken haben sich in der Regel vollkommen wohl gefühlt, namentlich aber nicht an Intermittens mit ausgesprochenen Anfällen gelitten, bis Oedeme an den unteren Extremitäten und ein allgemeines Unbehagen mit Schwächegefühl ihre Aufmerksamkeit erregen. Bei der ärztlichen Untersuchung findet man hochgradige Anämie, die Milz meist geschwollen, Oedeme an verschiedenen Körpertheilen, auch wohl leichten Ascites, den Urin eiweisshaltig mit spärlichen Cylindern. In einigen Fällen geben erst die Symptome der Urämie Veranlassung, ärztliche Hülfe nachzusuchen. Bei sorgfältiger Beobachtung gelingt es meistens leicht, Fiebererscheinungen nachzuweisen, doch ist manchmal die mehrmals täglich wiederholte Application des Thermometers hierzu erforderlich. . Bei systematischer Anwendung von Chinin und Eisen werden derartige Kranke leicht geheilt, doch bleibt gern eine Neigung zu Recidiven zurück. Bei Vernachlässigung oder falscher Behandlung freilich sind chronisches Siechthum und der Tod die gewöhnlichen Folgen. Obgleich ich leider nicht in der Lage bin, pathologisch-anatomische Befunde mittheilen zu können, halte ich doch eine besondere Bezeichnung dieser Nierenaffection als Nephritis malarica für gerechtfertigt.

\section{Lungenkrankbeiten bei Malariainfection.}

Ueber den Bronchialkatarrh bei Wechselfiebern ist schon früher gehandelt worden, hier soll die Schilderung der Lungenentzündungen und der so häufig aus ihr hervorgehenden Lungenschwindsucht Platz finden.

Die Lungenentzündung tritt in 2 Formen auf, als lobäre 
Pneumonie, welche in ihren objectiven Symptomen vollkommen der croupösen gleicht, und als Bronchopneumonie. Beide Formen sind in Vera Cruz häufig, beidèn geht meist Bronchialkatarrh voraus und nur in seltenen Fällen lassen sich die physikalischen Symptome der Lungenentzündung schon im ersten Anfall nachweisen. Eine sehr charakteristische Eigenthümlichkeit dieser Affectionen ist ihre Unstetigkeit, ihre Neigung von einem Lungenlappen auf den anderen oder von einer Lunge auf die andere überzuspringen. Es ist für den an den regelmässigen Verlauf einer croupösen Pneumonie gewöhnten Arzt ausserordentlich überraschend, die rapide Entwicklung alier Symptome, objectiver und subjectiver, während eines Anfalles und das eben so schnelle Versohwinden derselben in der Intermission zu beobachten. Noch wenige Wochen vor dem Niederschreiben dieser Zeilen behandelte ich ein junges Mädchen an einer im Tertiantypus auftretenden Entzündung des unteren Lappens der linken Lunge; erst nach 5 vollkommen typisch verlaufenden Anfällen gelang es die Krankheit zu heben; zweimal nahm auch der obere Lappen der rechten Lunge an der Entzündung Theil. Die Heilung war eine vollkommene. In anderen Fällen, namentlich wenn die Krankheit, wie sie es zu thun pflegt, sich in kürzeren oder längeren $Z$ wischenräumen wiederholt hat, bleiben chronische Entzündungen zurück und die Kranken gehen, oft erst nach Jahren, unter dem Bilde der chronischen Lungenschwindsucht zu Grunde.

Viel insidiöser ist die Malaria-Bronchopneumonie, welcher sehr viele Individuen, wenn die Natur des Uebels nicht zu rechter Zeit erkannt wird, erliegen. Ein einziger schlecht behandelter Anfall kann über das Schicksal des Kranken entscheiden und ihn rettungslos der Lungenschwindsucht, die daun nicht selten acut verläuft, anheimfallen lassen.

Dass wir es bei beiden Entzündungsformen mit einem specifischen, durch die Eigenthümlichkeit des Agens charakterisirten Prozess zu thun haben, ist selbstverständlich, auch ohne dass es bisher gelungen ist, diese Eigenthümlichkeit nachzuweisen. Es ist eine den Anforderungen der Zeit entsprechende interessante Aufgabe, die Sputa solcher Kranken auf etwaige Schizomyzeten zu untersuchen und dieselben mit denen der Tuberculose und der croupösen Lungenentzündung zu vergleichen. In einem weit vor- 
geschrittenen Falle, welcher tödtlich endigte, fand ich sowohl in den Sputis als im Blut ausserordentlich reichlich einen kleinen Micrococcus, doch glaube ich denselben eher als die Ursache des den Kranken aufreibenden septischen Fiebers und nicht als den Mikroorganismus der ursprünglichen Krankheit betrachten zu müssen.

Ehe freilich der Malariakeim nicht mit Sicherheit nachgewiesen worden ist, sind wir bei der Diagnose dieser Zustände auf den eigenthürnlichen Verlauf' und vorzüglich auf den Schluss ex juvantibus angewiesen. Der Erfolg der Chininbehandlung in frischen, aber nicht selten selbst in sehr vernachlässigten Fällen von längerer Dauer, ist ein so evidenter, dass an der specifischen Natur der Krankheitsursache nicht wohl gezweifelt werden kann. 'Die entzündlichen Lungenleiden bei Tuberculose, welche in Vera Cruz ebenfalls häufig ist, werden durch Chinin zwar gebessert, nie aber erreicht man einen so vollkommenen Nachlass aller Erscheinungen, wie bei den Malariapneumonien. Bei sehr stark inficirten Kranken bleibt oft kein anderes Mittel als Klimawechsel, aber radicaler. Ein böherer Beamter an der hiesigen englischen Eisenbahncompagnie, welcher seit 18 Jahren in der Tierra caliente und zum Theil in sehr bösen Malariadistricten, wie San Juan, Paso de Ovejas, Plan del hio lebt, hat schon dreimal eine mehrmonatliche Reise nach England antreten müssen, um dem fast unvermeidlich scheinenden Tode zu entgehen. Aus den physikalischen Symptomen bei der objectiven Untersuchung würde jeder mit diesen Affectionen nicht vertraute Arzt auf eine vorgeschrittene Lungentuberculose geschlossen habe, und doch kehrte der Kranke bis jetzt jedesmal vollkommen genesenvon seiner Urlaubsreise zurïck. Fälle dieser Art sind sehr geeignet, den grossen Gewinn für die Diagnose zu erläutern, welcher sich aus der mikroskopischen Untersuchung der Sputa wird ziehen lassen, weun erst die ätiologischen Verhältnisse vollkommen klar gelegt sein werden.

Dass Lungenschwindsucht aus Malariaaffection hervorgehen kann und in Vera Cruz thatsächlich sehr oft hervorgeht, kann nach meinen Erfahrungen und denen anderer hiesiger Collegen nicht bezweifelt werden, so sehr auch diese Auffassung mit der von Boudin aufgestellten und neuerdings von Jourdanet spe- 
ciell für Mexico eifrig vertheidigten Lehre vom Antagonismus der Malaria und der Lungenphthise im Widerspruch steht. Die Argumente Jourdanet's (Le Mexique et l'Amérique tropicale, Paris 1864) sind für jeden, welcher längere Zeit an der Ostküste Mexico's gelebt hat, geradezu unverständlich und ein glänzender Beweis dafür, wie weit man es bei einer vorgefassten Meinung in der Deutung der Thatsachen bringen kann. Die Häufigkeit der Lungenschwindsucht in Vera Cruz kann Jourdanet nicht leugnen, er muss aber seiner Theorie zu Liebe das endemische Vorkommen der Malariafieber abstreiten und erklärt dieselben für epidemische, was mit den Thatsachen im schreienden Widerspruch steht. Wenn er ferner ausführt, dass in Tabasco, dem Prototyp eines Fieberlandes, die Lungenschwindsucht nicht vorkomme, so ist auch dies nach den Mittheilungen zuverlässiger Collegen nicht richtig, wenn sie auch daselbst lange vicht in der Häufigkeit beobachtet wird, wie in Vera Cruz, Campeche und Tampico. Für die Erklärung ihres allgemeineren Vorkommens an gewissen Punkten der.0stküste Mexico's sind die in den Wintermonaten, von Ende September bis in den April herrschenden Nordwinde von Wichtigkeit. Diese Stürme, deren Heftigkeit an den verschiedenen Punkten der Küste sehr ungleich ist, erniedrigen die Temperatur oft in wenigen Stunden auf $14-12^{\circ} \mathrm{R}$; ; überbaupt erfolgt die Temperaturerniedrigung an den am meisten ausgesetzten und direct am Meere gelegenen Orten, wie die obengenannten, natürlich schneller und ausgiebiger, als bei weit von dem Meeresstrande. entfernt gelegenen Plätzen wie Tabasco (San Juan Bautista). Es kann nicht auffallen, dass durch diese Temperaturwechsel die Disposition zu Erkrankungen der Respirationsorgane bedeutend gesteigert wird und ebensowenig kann es überraschen, dass unter solchen Verhältnissen der Malariaprozess sich häufiger in den Lungen localisirt. Die beste Analogie hierzu bietet uns die neuerdings auch als Infectionskrankheit erkannte croupöse Pneumonie. Wenige Punkte in der Welt sind vielleicht so geeignet, wie die Hauptstadt Mexico, den Einfluss plötzlicher Temperaturwechsel auf die Entstehung derselben zu demonstriren. In Mexico kann man in einer und derselben Strasse oft zwei völlig verschiedene Klimate beobachten, auf der Sonnenseite lästige trockne Hitze und auf 
der Schattenseite eine unangenehm berührende Kühle; ausserdem sind in bestimmter Richtung verlaufende Strassen den abendlich sehr häufig von den schneebedeckten Vulkanen her wehenden eisigen Winden ausgesetzt, so dass beim Umbiegen um eine Strassenecke eine schroffe Temperaturveränderung bemerkbar wird, welche in den Sommermonaten noch empfindlicher ist, als in dem ohnehin ziemlich kühlen Winter. Die grösste Häufigkeit sowohl der croupösen Lungenentzündung als der acuten Erkältungsbrustfellentzündung fällt daher nicht auf den Winter, sondern in die Monate Juli und August. Ich muss bekennen, dass, als Jürgenssen lange vor der Entdeckung des Micrococcus die croupöse Lungenentzändung für eine Infectionskrankheit erklärte, ich durch die in Mexico gemachten Erfahrungen veranlasst wurde, Zweifel an der Richtigkeit seiner Theorie zu hegen. Wie Erkältungen den Ausbruch einer Infectionskrankheit begünstigen können, ist heute noch nicht völlig klar zu erkennen, an der Thatsache aber ist sowohl für die croupöse als die MalariaLungenentzündung, als auch für andere Erscheinungsformen der Malariainfection deswegen nicht $\mathrm{zu}$ zweifeln.

\section{Brustfellentzündung}

als Symptom der Malariainfection ist in Vera Cruz ebenfalls sehr häufig. Sie verläuft meist mit deutlichen Fiebererscheinungen, erlangt aber selten eine grosse Ausdehnung, sondern pflegt an mehreren disseminirten Punkten mit in den verschiedenen Anfällen wechselnder Intensität aufzutreten. In frischen Fällen verschwinden die Schmerzen, die Dämpfung, die Reibungsgeräusche während der Intermission vollständig, bei öfterer Wiederholung der Krankheit bleiben Rückstände derselben für längere Zeit bestehen. $\mathrm{Zu}$ bedeutender Exsudation habe ich es nie kommen sehen. Die Prognose ist bei richtiger Behandlung durchaus günstig.

Nicht dasselbe lässt sich von der

\section{Herzbeutelentzündung}

sagen, welche den schweren Malariaaffectionen zugerechnet werden muss. Die Exsudation ist oft eine beträchtliche und fast nie sind die Intermissionen vollständige. Sie kommt oft gleichzeitig mit Brustfellentzündung vor. 
Einem Falle von

Hämoglobinurie,

dem einzigen bisher in Mexico von mir beobachteten, habe ich eine besondere Mitheilung gewidmet.

4. Remittirende und continuirliche Fieber.

Dass das einfache Wechselfieber "öfter einen remittirenden Typus annimmt, ist schon früher erwähnt worden; die schweren Formen der remittirenden Fieber, namentlich die Remittens biliosa haemorrhagica sind in Vera Cruz ausserordentlich selten und kommen fast ausschliesslich in den Spitälern zur Beobachtung, was um so auffallender ist, als, wie gesagt, perniciöse Intermittenten in gewissen Schichten der Bevölkerung häufig vorkommen. Auch in Minatitlan, einem der berüchtigsten Fiebernester an der ganzen Küste, kommen schwere remittirende Fieber nur von Zeit zu Zeit epidemisch vor. Im Sommer 1878 hatte ich Gelegenheit, daselbst einige Fälle von Remittens haemorrhagica zu bejobachten, erhielt aber durchaus den Eindruck, dass es sich hier um eine eigenthümliche, von den Malariakrankheiten völlig verschiedene Affection handle. Die von mir bei einer anderen Gelegenheit (dies. Archiv Bd. 78) beschriebene auffallende Blutveränderung allein, die ich bei keinem ächten Malariafieber gefunden habe, muss Zweifel an der Identitït beider Prozesse erregen; auch der Umstand, dàss, wie mir von glaubwürdigen Leuten versichert wurde, das Ueberstehen eines Anfalls gegen eine neue Erkrankung schütze, wie bei gelbem Fieber, spricht entschieden gegen diese Identität. Herr Dr. Contreras, ein hiesiger gebildeter Arzt, welcher seit einer Reihe von Jahren in Tlacotalpam lebt, hat mir mitgetheilt, dass die Remittens haemorrhagica biliosa daselbst alljährlich während und kurz nach der Regenzeit vorkomme; er hält die Krankheit für verschieden von Malaria und führt zu Gunsten seiner Ansicht den Impfschutz, welchen ein Anfall gewährt, und die absolute Erfolglosigkeit der Chininbehandlung an.

Jedenfalls bleibt hier noch ein weites Feld für neue Untersuchungen, soviel aber glaube ich schon heute behaupten zu können, dass man nicht jedes Sumpffieber auch ohne Weiteres für ein Malariafieber erklären darf. 
VI. Die Malaria in der Hauptstadt Mexico.

Während eines 7 monatlichen Aufenthalts in der Hauptstadt Mexico's (von. November 1879 bis Anfang' Juni 1880) hatte ich Gelegenheit, die Erfahrungen und Ansichten der ältesten Aerzte über diesen Gegenstand kennen zu lernen. Alle versicherten einstimmig, dass noch vor 12-14 Jahren Malariafieber in Mexico so gut wie unbekannt waren und dass solche nur hin und wieder in den Spitälern an aus nahegelegenen Funkten der Tierra caliente, wie z. B. Cuernavaca, Cuautla u. s. w., zugereisten Kranken beobachtet wurden. Seit jener Zeit aber hat sich die Sachlàge allmählich vollkommen geändert, der Art, dass heute Malariafieber und sogar schivere Formen derselben als häufig bezeichnet werden müssen. Was die Ursache dieser auffallenden Erscheinung betrifft, so wird vielfach die durch vollständige Entwaldung des Thales von Mexico und dadurch veranlassten Wassermangel herbeigeführte Niveauerniedrigung und zu Zeiten theilweise Austrocknung der umliegenden Seeen, namentlich des Texcoco, beschuldigt; es ist aber klar, dass dieser Umstand allein nicht zur Erklärung hinreicht, da ein grosser Theil der. Stadt an und für sich auf Sumpfboden steht, wie Jourdanet sehr richtig hervorhebt. Sollte hier nicht ein Fall von Einschleppung und allmählicher Weiterverbreitung des Krankheitskeimes vorliegen? Gewiss ist es eine auffallende Thatsache, dass das Auftreten von Malaria in der Hauptstadt coincidirt mit der Eröffnung der Eisenbahnverbindung nach Vera Cruz und dem dadurch ganz bedeutend gesteigerten Verkehr mit der Küste.

Im Anschluss an die Betrachtung der Malariakrankheiten will ich hier noch einige Worte über das Vorkommen von Leberabscess an der Ostküste Mexico's hinzufügen, da, wie jch schón oben betont habe, derselbe meiner Ansicht nach, wenigstens in einer Reihe von Fällen, in inniger Beziehung zu Malariainfection steht.

Ueber Leberabscess an der Ostküste Mexico's.

Unter der ständigen Einwohnerschaft von Vera Cruz ist der Leberabscess selten: ich habe in 17 Jahren nur 10 Fälle beobachtet, von denen 8 Einheimische, 2 Fremde betrafen. Unter der 
flottirenden indianischen Arbeiterbevölkerung dagegen ist er ziemlich häufig. In dem Civilhospital wird man selten Fälle von Leberabscess vermissen, welche meistens Individuen aus der niederen arbeitenden Klasse betreffen. An anderen Punkten der Küste, namentlich Tampico, der Küste von Tabasco und Campeche, nimmt mit der Häufigkeit der Leberentzündung auch die Häufigkeit des Leberabscesses zu.

Dass für die Ostküste Mexico's ein inniger Zusammenhang von Malaria mit Leberabscess nicht wohl angezweifelt werden kann, ist schon oben erwähnt worden, es ist nur die Frage, wie man sich diesen Zusammenhang erklären und wie man die in anderen heissen Ländern gemachten Beobachtungen mit den hier mitgetheilten in Einklang bringen soll.

Vor Allem muss hervorgehoben werden, dass auch hier in einer Reihe von Fällen ein solcher Zusammenhang nicht besteht, dass dieselben vielmehr völlig analog den in anderen Ländern beobachteten verlaufen. Auch hier muss der Alkoholmissbrauch unter den prädisponirenden Momenten in erster Linie angeführt werden, ja der Umstand, dass der Trunk unter der indianischen sowohl als Mischlingsbevölkerung ein sehr verbreitetes Laster ist, erklärt uns zum Theil, warum hier die Einheimischen, wenn nicht mehr, so doch mindestens ebenso sehr, wie die Fremden, der Krankheit ausgesetzt sind.

Meiner Meinung nach darf der sogenannte idiopathische Leberabscess beisser Länder nicht als eine Krankheitseinheit betrachtet werden, man muss vielmehr mehrere Ursachen für denselben anerkennen, von denen je nach den Verhältnissen eine oder die andere vorwiegen kann. Ein Gemeinsames freilich liegt zu Grunde, dass, wie ich glaube, der Leberabscess der Tropen unter allen Omständen eine Infectionskrankheit ist: wechselnd ist nur die Natur des inficirenden Agens. Ich habe in 10 Fällen im hiesigen Civilspital den Eiter aus Leberabscessen sofort nach der Punction untersucht and jedesmal reichlich Mikroorganismen darin nachweisen können, in 9 Fällen ein und dasselbe Bakterium, in einem Falle einen sehr kleinen Micrococcus, den ich für identisch mit Micrococcus septicus halte. Dieser letztere Fall betraf einen Spanier, welcher nach einer schweren Dysenterie von Leberabscess befallen wurde und, obgleich die Punction 
unter scheinbar sehr günstigen Umständen von mir ausgeführt wurde, der Krankheit erlag. Dass hier, wie in manchen anderen Fällen, eine zufällige Infection unter Vermittlung des diphtherischen Prozesses auf der Darmschleimhaut stattgefunden hatte, ist wohl anzunehmen, auch ohne dass die Autopsie diesen $\mathrm{Zu}$ sammenhang klar dargelegt hat; das massenhafte Vorkommen des Micrococcus in dem frisch entleerten Eiter spricht deutlich genug. Den in den anderen 9 Fällen beobachteten Spaltpilz stelle ich, der Classification von Zopf folgend, vorläufig zu dem Genus Bacterium, da ich bisher nur Kokken- und Kurzstäbchenformen beobachtet habe. Ich kenne dieses Bacterium schon seit 8 Jahren, habe aber bisher mit der Veröffentlichung dieses Befundes zurückgehalten, da ich immer hoffte, bald Genaueres, namentlich in Bezug auf Cultivirung dieses niederen Pilzes, mittheilen zu können. Mangel an Zeit und Unerfahrenheit in der Praxis derartiger Experimente haben mich daran verhindert and seit ich mich im Besitze der neueren literarischen Hülfsmittel befinde, hat sich noch keine Gelegenheit geboten, die erworbenen Kenntnisse zu verwerthen. Um aber keinen $Z_{\text {weifel darüber }}$ aufkommen zu lassen, dass bei meinen bisherigen Beobachtungen die nächstliegenden Vorsichtsmaassregeln nicht ausser Acht gelassen worden sind, hebe ich hervor, dass alle Untersuchungen unmittelbar am Krankenbett angestellt wurden. Das Mikroskop stand bereit und der Eiter wurde direct aus der vorher sorgfältig gereinigten Potain'schen Flasche, gleich nach seiner Entleerung, durchmustert; auch auf Reinheit des Troicarts und der Gummischläuche wurde alle Sorgfalt verwendet. In jeder Probe liess sich unser Bacterium reichlich nachweisen, und habe ich dasselbe mehrfach hiesigen Collegen gezeigt.

Ich glaube aus diesen freilich sehr fragmentarischen Beobachtungen den Schluss ziehen zu dürfen, dass auch der Leberabscess der Tropen zu den Infectionskrankheiten gehört, wenn auch die Ursache der Infectionn icht immer die nämliche ist. Ohne mich allzuweit von dem Boden der Thatsachen zu entfernen, kann ich mir recht gut vorstellen, dass eine Spaltpilzinvasion, welche Malariafieber erzengt, unter Umständen anch zur Bildung eines Leberabscesses Veranlassung geben kann; man braucht nur vorauszusetzen, dass die Aufnahme des Krankheitskeimes hauptsächlich 
vom Darm aus erfolge und dass gewisse, freilich noch nicht näher zu definirende, prädisponirende Nomente für Leberentzündung vorhanden seien. Warum nicht in allen heissen Ländern ein $\mathrm{Zu}$ sammenhang zwischen Malariafiebern und Leberabscess nachweisbar ist, darüber können nur weitere Untersuchungen entscheiden, sei es, dass die Malariafieber verschiedener Gegenden nicht alle auf denselben Ursprung zurïckzuführen sind, was ich für sehr wahrscheinlich halte, sei es, dass, wie schon bemerkt, der Leberabscess tropischer Länder das Resultat verschiedenartiger Infectionen ist. Schon in Mexico haben wir ein schlagendes Beispiel von der polygenetischen Natur des Leberabscesses. Wie oben angeführt, waren in der Hauptstadt Mexico Malariafieber bis vor 14 Jahren so gut wie unbekannt, und doch ist der Leberabcess daselbst häufig, ja selbst häufiger als an der Küste: Dem vor wenigen Jahren verstorbenen Miguel Jimenez verdanken wir eingehende Mittheilungen über den Leberabscess in der Hauptstadt, welche es wohl verdienen, zu allgemeinerer Kenntniss gebracht zu werden. Am Ende dieses Abschnittes werde jch die ausgezeichnete Arbeit dieses bedeutenden mexicanischen Arztes ausführlich besprechen.

Jedenfalls würde eine Vergleichung der Leberabscesse an der Küste und in der Hauptstadt in Bèzug auf ihre Aetiologie im heutigen Sinne des Wortes von höchstem Interesse sein.

Wenden wir uns nun zur Erörterung einiger specieller, namentlich praktischer Fragen.

Der frisch entleerte Eiter eines Leberabscesses hat einen eigenthümlichen, aber nie auch nur entfernt an Fäulniss erinnernden Geruch und ist im Allgemeinen ziemlich dickflüssig. Der Farbe nach lassen sich zwei Arten unterscheiden: der graugelbe und der mehr oder wenig tief ziegelroth gefärbte Lebereiter, welcher letzterer offenbar einer Beimischung von Blut und nachträglicher allmählicher Veränderung des Blutfarbstoffs seine Farbe verdankt. In den von mir untersuchten Fällen habe ich frische rothe Blutkörperchen meist nicht mehr auffinden können, weisse Blutkörperchen und Eiterkörperchen sind meist wie in jedem Eiter zu finden, doch werden sie bei alten, in Eindickung begriffenen Abscessen, wenn keine neue Entzündungsnachschübe stattgefunden haben, zuweilen vermisst. Man findet dann nur 
ungeheure Mengen von organischem Detritus, welcher übrigens auch in jedem frischen Lebereiter vorkommt. Von sonstigen mikroskopisch nachweisbaren Bestandtheilen sind $\mathrm{zu}$ erwähnen: 1) mehr oder weniger zahlreiche Fetttropfen, 2) Krystallbüschel, welche sich unschwer als Fettsäurekrystalle erkennen lassen und 3) eine Reihe anderer von mir nicht näher untersuchter Krystalle. Eine vollkommene Analyse des Lebereiters habe ich leider aus Mangel an Hülfsmitteln nicht anstellen können.

Bei der künstlichen Entleerung durch die Bauchdecken treffen wir fast eben so oft den graugelben, als den rothen Eiter; wo dagegen ein natürlicher Durchbruch des Abscesses in die Bronchien oder in den Darm erfolgt, erscheint fast ausnahmslos der rothe Eiter, was in den, einen solchen Durchbruch wohl unvermeidlicher Weise begleitenden Blutungen seine Erklärung findet. Dieser Umstand ist, wie ich schon in meiner ersten kurzen Mittheilung über den Leberabscess hervorgehoben babe, in zweifelhaften Fällen von entscheidender Bedeutung und genügt sogar für den Kenner, um ohne weiteres die Diagnose auf Leberabscess zu stellen.

Bei der Behandlung des Leberabscesses müssen wir die prophylactische von der gegen die ausgebildete Krankheit gerichteten unterscheiden.

Die prophylactische Behandlung ist gegen die Hepatitis gerichtet, falls dieselbe nicht, wie es zuweilen vorkommt, symptomlos verläuft. Einen derartigen Fall habe ich schon in meiner ersten Mittheilung erwähnt; 2 andere sind von mir seitdem beobachtet worden, beide ältere Männer betreffend, bei denen erst wenige Tage vor dem Durchbruch, welcher in beiden Fällen in die Bronchien erfolgte, sich Fieber, Schmerzen und Athembeschwerden einstellten. Beide Fälle endigten mit Genesung, - ein neuer Beweis dafür, dass Durchbruch in die Lungen als der günstigste Ausgang eines Leberabscesses angesehen werden muss. Im Ganzen habe ich 6 mal diesen Ausgang beobachtet und jedesmal war derselbe ein günstiger.

Entwickelt sich Hepatitis im Laufe eines Malariafiebers, so ist energische Chininbehandlung die Hauptsache und reicht meiner Erfahrung nach meistens zur Beseitigung derselben aus. Seltener wird man auch in diesen Fällen zur Anwendung localer 
Blutentziehungen zu schreiten haben. Eine Nacheur von künstlichem Karlsbader, Vichy oder in leichteren Fällen von FranzJoseph-Bitterwasser unterlasse ich niemals.

Bei Hepatitis aus anderer Ursache sind dagegen locale Blutentziehungen in erster linie zu nennen und oft habe ich auf Application von Blutegeln mit nachfolgender Anwendung warmer Breiumschläge selbst sehr schmerzhafte und harte Leberanschwellungen vollkommen zurückgehen sehen. Abführmittel sowohl während des Anfalls, als in der Nachour, sind fast immer erforderlich und auch von entschiedenstem Nutzen. Mit Vorliebe verwende ich während des Anfalles eine ziemlich concentrirte Jössung von Karlsbader Salz, in leichteren Fällen FranzJoseph-Bitterwasser oder Seidlitzpulver. Calomel in grossen abführenden Dosen oder Ricinusöl verschreibe ich, wo gleichzeitig Dysenterie besteht; von der Anwendung des Calomel in kleinen Dosen aber, wie sie trotz alier Misserfolge von den hiesigen Aerzten noch immer angewendet werden, muss ich entschieden abrathen; vollständige Störung der Verdauung und Vernichtung des ohnehin schon mangelnden Appetits sind die einzigen nachweisbaren Ergebnisse dieser Behandlung. Als Nachcur lasse ich stets Karlsbader- oder Vichywasser gebrauchen.

Bei der Behandlung des ausgebildeten Abscesses gelten zunächst dieselben Gesichtspunkte, wie bei der der Hejatitis, und kommen daher auch ganz dieselben Mittel zur Anwendung. Vor der Anwendung von kleinen Dosen Calomel muss ich hier noch entschiedener warnen, denn sie tragen durch ihren schädlichen Einfluss auf den Appetit und die Verdauung in hohem Grade zur Entkräftung der Kranken bei. Was die Anwendung des Chinins betrifft, muss ich dieselbe auf das Entschiedenste empfehlen: 1) in allen Fällen, wo eine Malariainfection zu Grunde liegt, 2) in sich lange hinziehenden Fällen, wenn die Kräfte des Kranken unter den täglichen Fieberanfällen sich zu erschöpfen drohen. Sehr häufig spottet freilich das Fieber selbst der energischsten Chininbehandlung, allein der eclatante Erfolg, welchen ich einige Male von derselben gesehen habe, rechtfertigt meine warme Empfehlung. Ich kann es mir nicht versagen, einen dieser Fälle kurz mitzutheilen.

Hers B., ein geachteter Deutscher, welcher in Catemaco 
einer grossen Kaffeplantage vorstand, hatte schon Jahre lang wiederholt an Malariafiebern gelitten und im Verlauf derselben eine chronische Hepatitis acquirirt. Es verdient bemerkt zu werden, dass Herr B. ein durchaus mässiger Mann war, welcher nie einen groben Excess beging und Branntwein überhaupt nicht trank. Derselbe consultirte mich vor $4 \frac{1}{2}$ Jahren zum ersten Male und wurde vollkommen hergestellt, erschien jedoch 2 Jahre später wieder bei mir mit einem Rückfall seines alten Leidens, welches diesmal nicht vollständig zurückging. Acht Monate später präsentirte sich mir unser Landsmann in der traurigsten Verfassung mit allen Symptomen eines offenbar fast den ganzen rechten Lappen in Anspruch nehmenden Abscesses der enorm vergrösserten Leber; seine Kräfte waren durch die täglichen, mehrere Stunden anhaltenden Fieberanfälle mit nachfolgenden profusen Schweissen auf das Aeusserste erschöpft, der Appetit lag völlig darnieder. Ich verordnete Milch und kräftige Fleisch. brühe and täglich $3 \mathrm{mal} 0,5$ Chinin. bisulfuric. und hatte die Genugthuung, das Fieber nach 4 Tagen verschwinden zu sehen. Bei leichter kräftigender Ernährung hoben. sich allmählich die Kräfte der Art, dass der ungeduldige Patient nun mit Energie auf die Ausführung der Operation drang, welche ich jedoch in der Hoffnung; der Abscess werde endlich Neigung zeigen, an irgend einer Stelle nach aussen durchzubrechen, verweigerte. Trotz meines Abrathens liess sich der Kranke nicht halten, reiste nach Mexico und erlag daselbst wenige Tage später den Folgen der Punction. Dieser Fall ist nicht nur wegen der augenfälligen Wirkung des Chinins, sondern auch deshalb interessant, weil er ganz gegen die allgemeine und gewiss im Ganzen richtige Vorschrift, Leberabscesse so früh als möglich zu öffnen, beweist, dass es unter Umständen besser ist abzuwarten und nicht vorzeitig eine gewaltsame Entscheidung herbeizuführen. Ich ersehe übrigens aus der Darstellung der suppurativen Hepatitis von Thierfelder im Ziemssen'schen Handbuch, dass schon Cambay und Jaccoud die Anwendung des Chinins gegen das Fieber bei Leberabscess empiohlen haben, obgleich diese Empfehlung als ganz vereinzelt dastehend bezeichnet wird. Nach meinen Erfahrungen muss ich die Angaben dieser Aerzte bestätigen. 
Grosse Blasenpflaster, auf die Lebergegend applicirt, sind in einzelnen Fällen unzweifelhaft von günstiger Wirkung; dass sie aber die Ausbildung eines drohenden Abscesses verhindern können, wie ich vom Chinin und von localen Blutentziehungen anzunehmen mich berechtigt glaube, davon habe ich mich nicht überzeugen können.

Was die Operation der Leberabscesse betrifft, muss leider eingestanden werden, dass die Resultate derselben bis jetzt ausserordentlich ungünstige gewesen sind. In meiner Privatpraxis hatte ich nur 2 mal Gelegenheit die Punction auszufübren, einmal in einem verzweifelten Falle, das andere Mal unter scheinbar sehr günstigen Umständen, und doch endigten beide Fälle tödtlich. Unter einigen 20 Operationen, denen ich im hiesigen Civilspital beiwohnte, führten nur 2 zui Genesung. Allgemein üblich ist hier schon seit Jahren die Anwendung von Aspiratoren, namentlich des Potain'schen Apparats. Hoffentlich wird die Einführung des antiseptischen Verfahrens auch auf diesem noch so wenig erfreulichen Gebiete der Chirurgie eine neue Aera schaffen.

Ich schliesse hier eine Beobachtung über Abscess der Gallenblase in Folge von Gallensteinanhäufung bei einer 70jährigen Frau an, weil ich in diesem Falle die Cholecystotomie unter antiseptischen Cautelen ausführte, soweit überhaupt hiervon die Rede sein kann, wenn man, wie ich, das antiseptische Verfahren nur aus Büchern kennt. Ich entleerte mehr als 30 grössere Steine und eine Menge Steingries und hatte auch die Freude, die bejahrte Kranke, was die Folgen der Operation betraf, in 14 Tagen hergestellt zu sehen, dieselbe erlag aber 3 Monate später einem schon seit längerer Zeit bestehenden chronischen Darmkatarrh.

Nicht ohne Interesse für das Verhältniss der suppurativen Leberentzündung zur Lebercirrhose dürfte die Bemerkung sein, dass letztere unter den dem Branntwein- und Pulque-Genuss ergebenen Schichten der Bevölkerung ausserordentlich häufig ist, ein schlagender Beweis dafür, dass nicht etwa, wie man geglaubt hat, blos in Folge des Klimas die Leberentzündung der Säufer in tropischen Ländern mehr zur Eiterung als zum chronischen Verlauf neige.

Zur Vervollständigung des Gesagten füge ich noch Folgendes hinzu. 
Leberkrebs habe ich in Vera Cruz 5 mal beobachtet, 3 mal bei Einheimischen, 2 mal bei Fremden.

Gallensteine und ihre Folgekrankheiten sind hier ausserordentlich häufig, namentlich unter der eine sitzende Lebensweise führenden und im Allgemeinen an trägem Stuhlgang leidenden weiblichen Bevölkerung.

\section{Miguel Jimenez, Ueber den Leberabscess in der Hauptstadt Mexico.}

Im Jahre 1858 veröffentlichte Miguel Jimenez die in 18jähriger Praxis erworbenen Erfahrungen über den Leberabscess in Form von klinischen Vorträgen unter dem Titel: Clinica medica, Lecciones dadas en la Escuela de Medicina do Mexico, por el Catedratico del Ramo Miguel F. Jimenez. Mexico. Imprenta de M. Murguía, Portal del Agila de Oro, 1858.

An 15, in mustergültiger Weise mitgetheilten-Krankengeschichten, deren jeder äusserst lehrreiche und gehaltvolle Auseinandersetzungen und Betrachtungen folgen, erörtert der Verfasser. Entstehung, Symptome, Verlauf, Ausgänge und Behandlung des Leberabscesses. Ich will versuchen, in kurzen Worten den wesentlichen Inhalt der 7 Capitel, welche das Werk umfasst, wiederzugeben.

1. Capitel. Von 289 Fällen von Leberabscess wurden beobachtet im

\begin{tabular}{cr} 
Monat Januar & 9 \\
- Februar & 11 \\
- März & 22 \\
- April & 25 \\
- Mai & 78 \\
- Juni & 47 \\
- Juli & 32 \\
- August & 21 \\
- September & 18 \\
- October & 12 \\
- November & 9 \\
- December & 5 \\
\hline \multicolumn{2}{c}{ Summa 289.}
\end{tabular}


Der. Monat Mai ist in der Hauptstadt durchschnittlich der heisseste. Dem Alter nach vertheilen sich 232 Fälle von Leberabscess in folgender Weise:

$$
\begin{aligned}
& \text { Von 18-28 Jahren } 27 \\
& \text { - } 28-38-54 \\
& \text { - } 38-48 \text { - } 66 \\
& \text { - 48-58 - } 49 \\
& \text { - 58-68 - } 17 \\
& \text { - } 68-78-15 \\
& \text { - } \frac{78-88-\quad 4}{\text { Summa } 232 .}
\end{aligned}
$$

Unter 76 Fällen, bei welchen die Veranlassung der Krankheit festgestellt werden konnte, wurden verursacht:

durch eine schwere Indigestion . . . . . . 28 Fälle durch forcirte Märsche und Uebungen . . . . 23 durch Gemüthsbewegungen, hauptsächlich Aerger 17 durch in der Tierra caliente acquirirte Dysenterie 4 durch Hämorrhoidalleiden . . . . . . . . . 2 durch Contusion in der Lebergegend. $\frac{. .22-}{\text { Summa } 76 \text { Fälle. }}$

Es ist nicht, wie Verfasser ausführt, die gewöhnliche Unmässigkeit, noch irgend welche Indigestion, welche zum Leberabscess führt; dies wird schon zur Genüge durch die grosse, im Hospital 2 Säle füllende Masse von an den Folgen des Alkoholismus leidenden Kranken widerlegt, bei denen sich wohl andere Leberkrankheiten finden, aber kein Leberabscess. Um einen Abscess herbeizuführen, bedarf es einer Orgie, in welcher schwer verdauliche Speisen zusammen mit stark alkoholischen Getränken genossen werden. Es scheint sogar in einzelnen Fällen, als ob die unverdaulichen Substanzen, auf dem Wege der Pfortader der Leber zugéführt, die Eiterung erregen, ohne eine vorangehende Entzündung.

Gegenüber den zahlreichen europäischen Beobachtungen über metastatische Leberabscesse nach Kopfwunden hebt der Verf. hervor, dass er bisher in Mexico nur einen solchen Fall gesehen habe.

2. Capitel. Die der Bildung eines Abscesses vorausgehende Hepatitis ist charakterisirt durch Zunahme des Volumens 
der Leber, Schmerz in der Lebergegend und in Schulter, Rücken und Arm der rechten Seite, Athembeschwerden, Hipo, Uebelkeiten, Erbrechen, Magensäure, Aufstossen, bitteren Geschmack im Munde, Durst, Beschränkung der Stuhlentleerungen und Entfärbung der Fäces, icterische Färbung der Haut und des Urins und - Fieber.

Mit der Ausbildung des Abscesses modificiren sich die Symptome in folgender Weise. Das Volumen der Leber nimmt rasch in sichtlicher Weise, oft von einem Tag zum andern zu, nach unten häufig bis zum Nabel, auch in einzelnen Fällen bis zur Crista ilium, nach oben bis zur Brustwarze und einige Linien darüber, nach der Mitte und links, das Epigastrium vorwölbend, nach rechts die letzten 5 oder 6 Rippen nach aussen drängend und die Intercostalräume erweiternd, - Volumenveränderungen, welche natürlich bedeutend von der Lage und Grösse des Abscesses beeinflusst werden. Verf. erörtert sodann die weitere Ausdehnung der Dämpfung nach oben in den Fällen, wo der Abscess das Zwerchfell durchbohrt und einen Ausweg durch die Pleura und die rechte Lunge sucht, und macht auf die Irrthümer anfmerksam, welche in Bezug auf rechtsseitige Pleuritis und Pneumonie entstehen können. Andrerseits warnt er davor, grosse Lebertumoren bei Akoholikern oder nach Malariaaffectionen, wenn sich zufällig in ihnen eine acute Hepatitis entwickelt, auf Leberabscess zu beziehen, zumal solche Tumoren zuweilen Fluctuation vortäuschen können.

Der Schmerz verhindert bei ausgebildetem Abscess den Kranken, sich auf die rechte oder linke Seite zu legen, auf die rechte wegen der Steigerung desselben, auf die linke wegen des Gefühls eines nach dorthin fallenden Gewichts. Die Kranken nehmen daher die Rückenlage ein, mit leichter Neigung nach rechts. Der Schulterschmerz verschwindet zuweilen, in anderen Fällen aber stellt er sich erst jetzt ein; 11 mal sah Verf. ihn sich bis auf die letzten 2 Finger der rechten Hand ausdehnen, gleichzeitig mit Gefühl von Taubsein in denselben. Die grösste Wịchtigkeit legt Verf. einem fixen, umschriebenen und oberfiächlichen Schmerz bei, der sich in einem oder mehreren der zwischen der 7. und 10. Rippe gelegenen Intercostalräume befindet und auf Druck erheblich zunimmt; er ist ein guter Führer zur Auffindung der Fluctuation. 
Die icterische Färbung der Haut und des Urins, welche übrigens bei der Hepatitis niemals so hochgradig ist, wie z. B. bei Verstopfung der Gallenwege, pflegt in der Mehrzahl der Fälle zu verschwinden. Von den Verdaunngsstörungen pflegt das Erbrechen anzuhalten, namentlich tritt es nach jeder Nahrungszufuhr auf. Die Verstopfung schwindet im. Allgemeinen bei fortschreitender Eiterung und macht sogar in der letzten Periode Diarrhöen Platz, welche ein sicheres Zeichen für eingetretene Zersetzung des Eiters abgeben. Sehr hartnäckiger Hipo deutet auf Theilnahme des Zwerchfells und Neigung zum Durchbruch durch die Lunge.

Der Puls verliert bei Eintritt der Eiterung seine Härte, er wird weicher und zusammendrückbarer, die Temperatur steigt, es treten Calosfrios (ich brauche absichtlich das sehr bezeichnende spanische Wort) ein, und zuweilen sehr reichliche Schweisse, hauptsächlich im Schlaf und den letzten Nachtstunden. In 23 Fällen fehlten die Calosfrios, in 37 die Schweisse und in 11 beide Symptome.

Nachdem Verf. nun die Wichtigkeit des Auffindens der Fluctuation behandelt hat, erörtert $e r$ sehr ausführlich die Momente, welche auf das Bestehen von Adhärenzen mit den Bauch- oder Brustwandungen sprechen. Bei Abscessen in der Regio epigastrica ist unter Umständen die Diagnose sehr einfach. wenn der Eiter schon die Bauchdecken selbst corrodirt hat. Die Umschriebenheit der stark hervorragenden Geschwulst, die Veränderung der Hautfarbe, die Unbeweglichkeit der Haut über ihrer Unterlage, die Pastosität der Gewebe und die oberflächliche Fluctuation gestatten die Eröffnung des Abscesses mit voller Sicherheit. Allein diese Fälle sind die seltensten, und wollte man immer so lange warten, bis diese Symptome sich einstellen, so würde meist der Tod vor Sicherstellung der Diagnose eintreten. Wo der Eiter tiefer sitzt und noch durch Lebergewebe von den Bauchdecken getrennt ist, fehlen alle diese Zeichen, wohl aber muss man dann feststellen, ob bei Lageveränderungen des Kranken auf die eine oder die andere Seite die Geschwulst den Bewegungen folgt oder nicht, ob der Ort der Fluctuation dabei seine lage verändert oder nicht, ob die Baucbwandungen, wenn ihre Schlaffheit es gestattet, sie zwischen dio Finger zu nehmen, 
auf der Leberoberfläche verschiebbar sind oder nicht. Existirt ein leichter Ascites, so muss man nach Jimenez untersuchen, ob bei rechter Seitenlage des Kranken die Flüssigkeit frei zwischen Leber und Bauchdecken eintreten kann oder an einer gewissen Stelle zurückgehalten wird, was man bei Anwendung vou abwechselnden Stössen mit der flachen Hand erfährt, die stark genug sind, um bis auf die Leber zu gelangen, - ein Verfahren, welches Verf. auch bei anderen Unterleibstumoren empfiehlt und als Sucusion hydro-abdominal bezeichnet. Ein Ietztes Hülfsmittel, um das Bestehen von Adhärenzen zu beweisen, ist das Reibungsgeräusch, welches sich synchronisch mit den Respirationsbewegungen an den Bauch- oder Brustwandungen durch die Auscultation nachweisen lässt. Von allen genannten Symptomen genügt nach den Erfahrungen des Verf., und dieser Punkt ist für die Praxis von höchster Wichtigkeit, der Nachweis von Fluctuation in einem Intercostalraum, um mit voller Sicherbeit auf Verwachsungen zu rechnen und ohne Furcht die Operation an dieser Stelle auszuführen. Am Schluss dieses wichtigen Capitels citirt Verf. einen Fall von Leberabscess, in welchem unter Berücksichtigung aller Umstände die Diagnose auf Magenkrebs gestellt worden war, - ein Beweis " für die grosse Schwierigkeit derselben in einzelnen Fällen.

3. Capitel. In 34 Fällen, in welchen die Eröffnung nicht durch die Bauchdecken erfolgte, kam dieselbe zu Stande:

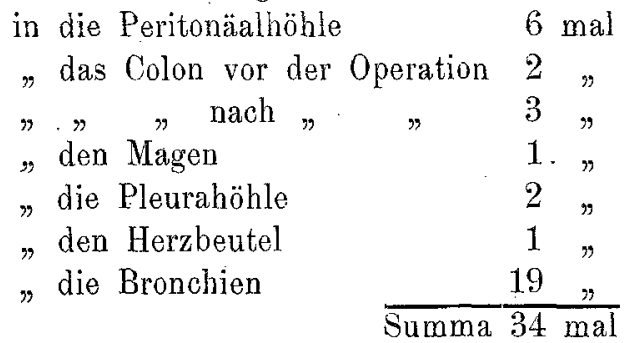

Verf. bespricht die in vielen Fällen leichte Diagnose dieser Zufälle, macht aber gleichzeitig auf die sich zuweilen darbietenden Schwierigkeiten derselben aufmerksam. Er citirt einen Fall, in welchem Leberabscess diagnosticirt war und sich in der Leiche ein Lungenabscess vorfand.

4. Capitel. Die Dauer des einmal gebildeten Leberab- 
scesses ist eine sehr verschiedene, im Allgemeinen aber eine lange, von einem bis zu mellreren Monaten, ja selbst bis $2 \frac{1}{2} \mathrm{Jahr}$. 5. Capitel. Von 297 Fällen von Leberabscess endigten 242 tödtlich, es genasen also nur 18 pCt. Für den Ausgang, sei es in Tod, sei es in Genesung sind entscheidend 1) dic Constitution und Individualität des Kranken, 2) die Grösse und Tiefe des Abscesses, 3) die Art des Aufbruches desselben. Durchbruch in die Peritonäal-, Pleura- oder Pericardialhöhle bedingt unmittelbar den Tod. Von 5 Fällen mit Durchbruch in das Colon endigten 3 tödtlich, 1 Fall mit Eröffnung in den Magen endigte ebenfalls tödtlich, dagegen genasen von 19 Fällen mit Durchbruch durch die Bronchien 12. Dieser Ausgang muss also als der gïnstigste bezeichnet werden. 4) die Schwere und Dauer der colliquativen Erscheinungen.

6. Capitel. Der Leberabscess hat eine entschiedene Vorliebe für den rechten Leberlappen; Abscess des linken Lappens hat Verf. nur als Complication mit dem des rechten beobachtet. Nie fand sich ein Abscess im Lobulus Spigelii. Meistens findet sich nur ein Abscess bei der Autopsie, wenn auch die Unregelmässigkeit der Abscesshöhle und die Persistenz von Scheidewänden und Balken in vielën Fällen auf die Entstehung aus mehreren Heerden hinweisen. Mehrere Abscesse wurden in nur 6 pCt. aller Fälle beobachtet. Der Eiter ist nach Jimenez meist blutig gefärbt, von der schon erwähnten charakteristischen Färbung des Lebereiters, nur bei kleineren Heerden kam nicht zu selten auch gelblich-grünlicher Eiter zur Beobachtung, was auffallend init meineu an der Küste gemachten Erfahrungen contrastirt.

7. Capitel. Gegen die Hepatitis empfiehlt Verf. in erster Linie Blutentziehungen und Abführmittel. Was die Blutentziehungen betrifft, zieht er die allgemeinen den localen vor, welche nur bei Stockungen der Menstruation oder eines Hämorrhoidalflusses vortheilhaft und dann am After vorzunehmen seien. Unter den Abführmitteln giebt er den salinischen den Vorzug, gesteht aber ein, dass alter Routine zufolge meist Calomel in abführender Dose angewendet werde. Häufige Bäder von langer Dauer und Blasenpflaster vervollständigen die Behandlung.

Bei ausgebildetem Abscess ist Entleerung desselben die Hauptaufgabe. 
Die nächste Frage ist die nach dem Bestehen von Adhärenzen. Fehlen dieselben, so folgt Verf. der Methode von Begin oder Recamier, die definitive Eröffnung geschieht aber in allen Fällen am besten mit dem Troicart nach Erhebung einer Hautfalte. Den Schnitt mit dem Bistouri empfiehlt Verf. nur als vorbereitendes Verfahren. Dabei wird nochmals daran erinnert, dass Fluctuation in einem Intercostalraum mit Sicherheit anf die Anwesenheit von Verwachsungen schliessen lässt.

Soweit der Verf. Ich bin in meinem Referat etwas ausführlich gewesen, weil ich bei der Unbekanntschaft europäischer Collegen mit dem Leberauscess der Tropen dadurch der Wissenschaft einen Dienst zu leisten glaubte, und um dem Gedächtniss eines Mannes gerecht zu werden, den wir den bedeutendsten Klinikern seiner Zeit beizählen müssen.

\section{Kurze Bemerkungen über einige andere Infections- krankheiten.}

Die Masern treten in Vera Cruz fast alljährlich auf und zwar in den kühleren Monaten. Es ist hervorzuheben, dass Recidive, oft schon in der nächsten Epidemie, sehr häufig sind. Der Krankheitsverlauf ist durchgehend ein günstiger.

Scharlach, den ich in den ersten 6 Jahren meines Aufenthaits vermisst hatte, ist seitdem 3 mal, 1878, 1882 und 1883 in leichten Epidemien aufgetreten. Der Verlauf ist durchaus günstig, sehr im Gegensatz zu den mörderischen Epidemien, von denen schon Orizaba heimgesucht wird, eine Stadt, welche nur 36 Leguas von Vera Cruz entfernt, aber allerdings schon etwa 3800 Fuss über dem Meeresspiegel erhaben ist.

Die Blattern, welche sich während meines Aufenthalts $4 \mathrm{mal}$ in grösserem Maassstabe zeigten, lassen keine Modification ihres-Verlaufes durch das heisse Klima erkennen.

Der Keuch husten verläuft hier durchaus gutartig; ich habe in 18 Jahren nur von einem Todesfall gehört, während in Mexico die Sterblichkeit an dieser Krankheit eine sehr bedeutende ist.

Die epidemische Diphtherie ist in Vera Cruz eine sehr häufige Erscheinung. Ohne mich auf weitere Discussion der verschiedenen empfohlenen Behandlungsmethoden einzulassen, 
will ich die meinige, nun schon seit 12 Jahren mit sehr befriedigendem Erfolge geübte, kurz anführen. Ich behandle sowohl die sporadische Diphtherie, wenn sie mit Fieber auftritt, als auch die epidemische, wesentlich nur mit Chinin. Hervorzuheben ist, dass ich bei fiebernden Kindern täglich den Schlund untersuche. Kindern verordne ich täglich 3 mal $0,3-0,4$ Chinin. bisulfuric. in Lösung, Erwachsenen 3 mal täglich 0,5 Chinin. bisulfuric. in Gallertkapseln und zwar so lange, bis das Fieber vollständig geschwunden ist und die Localerscheinungen ihren progressiven Charakter verloren haben. Dabei für Erwachsene Gurgelwasser von 2 pCt. Acid. carbolic., bei Kindern mehrmals täglich Auspinselungen mit derselben Lösung. Dies neben möglichst kräftiger Ernährung ist meine ganze Behandlung und kann ich versichern, dass ich seit consequenter Durchführung derselben, bei 20-30 Fällen, welche jährlich durch meine Hände gehen, nur einen Todesfall zu beklagen gehabt habe, während in früheren Jahren die Sterblichkeit an Diphtherie in meiner Praxis nicht geringer war als an anderen Orten. Der einzige Todesfall betraf ein Kind, welches in Orizaba ein schweres Scharlachfieber durchgemacht hatte und, kaum in Reconvalescenz, von Conjunctivitis crouposa befallen wurde. Während ich dieses sich überaus hartnäckig zeigende Uebel zu bekämpfen suchte, entwickelte sich plötzlich Diphtherie der Nasenhöhlen und des Schlundes, ohne dass deshalb die Conjunctivitis ihren rein croupösen Charakter veränderte, und trotz aller meiner Anstrengung erlag das Kind der Krankheit.

Von diesem complicirten Falle abgesehen, verdienen die Erfolge der consequenten Chininbehandlung gewiss alle Beachtung von Seiten der Fachgenossen. Freilich muss erst die Erfahrung darüber entscheiden, ob auch im gemässigten oder kalten Klima der Erfolg derselbe sein wird, für das heisse Klima aber, so kann ich dreist behaupten, besitzen wir in dem Chinin ein so gut wie unfehlbares Mittel gegen eine der mörderischsten Infectionskrankheiten.

Denselben sichtlichen Erfolg habe ich von der consequenten Chininbehandlung noch bei einer anderen Infectionskrankheit, nehmlich bei der Gesichtsrose beobachtet. Meist ist schon in 24 Stunden der Nachlass ganz auffallend, 
Typhus, sowohl exanthematischen als Abdominaltyphus, habe ich auch seit meiner letzten Mittheilung, also im Ganzen seit 18 Jahren in Vera Cruz nicht beobachtet, und Gleiches wird mir von zuverlässigen Collegen aus anderen Küstenplätzen berichtet. Es ist dies um so auffallender, als schon in der Höhe von Cordova und Orizaba Typhen beider Kategorie keine ganz seltene Erscheinung sind und in Mexico sogar eine Hauptplage der Bevölkerung bilden.

In Bezug auf das Mal de pintos theile ich einer Bemerkung bei Hirsch wegen mit, dass dasselbe auch an den östlichen Abhängen der Cordilleren und zwar an denen der Sierra. von Oaxaca nach der Küste zu in einigen Indianerdörfern vorkommt, doch sind mir leider mit Ausnahme von Soyaltepec die Namen derselben augenblicklich nicht gegenwärtig.

\section{Bemerkungeu zur Aetiologie des Spasmus glottidis.}

Bei dem Studium der 2. Auflage des Cohnheim'schen Werkes über allgemeine Pathologie fiel es mir auf, dass eine von mir vor nun schon seit 22 Jahren in wenig Worten mitgetheilte Beobachtung, welche wohl geeignet ist, bei der Frage nach der Aetiologie des Spasmus glottidis berücksichtigt zu werden, vollkommen unbeachtet geblieben ist.

In der von Dr. Posner redigirten "Allgemeinen medicinischen Centralzeitung " vom 16. August 1862 theile ich zugleich mit der Beschreibung des Reflexverhältnisses zwischen den MagenDarmverzweigungen des Bauchsympathicus und den Herzästen des Vagus wörtlich Folgendes mit: Uebrigens werden nicht nur die Herzäste, sondern, was ebenfalls von pathologischem Interesse ist, sehr regelmässig auch die zur Stimmlade tretenden Vagusäste reflectorisch erregt; man beobachtet bei dem eben beschriebenen Versuch Schluss der Stimmritze, zuweilen Erweiterung. Wenn auch diese Versuche nur an Fröschen angestellt waren, so machten sie immerhin auf ein besonderes Reflexverhältniss aufmerlsam, welches wahrscheinlich auch für die höheren Wirbelthiere Geltung hat. 